\title{
Unión Europea-Cuba: relación compleja, futuro incierto
}

\author{
European Union-Cuba: complex relationship, uncertain future
}

\section{Eimys OrTIZ}

Profesora Asociada de Derecho Internacional Público

Universidad de Lleida

eortiz@dpub.udl.cat

Resumen: El objeto de este trabajo es analizar las relaciones entre la Unión Europea y Cuba desde una perspectiva histórico-jurídica. Desde que en 2014 se abriese el proceso de conclusión del primer vínculo jurídico entre La Habana y Bruselas -el Acuerdo de Diálogo Político y Cooperación-, los dos métodos, a veces antagónicos, el europeo, con la diplomacia pragmática, y el norteamericano, con el aislamiento, han ido acercando posturas hacia el mismo objetivo: acelerar la transición política del país. A pesar de los esfuerzos, las autoridades cubanas siguen enrocadas en una visión tradicional que puede llegar a debilitar lo conseguido hasta el momento.

Palabras claves: Unión Europea, Cuba, Acuerdo de Diálogo Político y Cooperación, Estados Unidos.
Abstract: The purpose of this work is to analyse the relationship between the European Union and Cuba from a historical-legal approach. Since the process to conclude the first legal link -Political Dialogue and Cooperation Agreement-, between Havana and Brussels was opened in 2014, the two methods, which sometimes were opposed, the European one with a pragmatic diplomacy, and the NorthAmerican with its isolation, have tried to align positions towards the same objective: to accelerate the political transition of the country. Despite the efforts, the Cuban authorities continue insisting on a traditional view that could weaken what has been achieved so far.

Keywords: European Union, Cuba, Political Dialogue and Cooperation Agreement, United States of America.
Résumé: L'objectif de ce travail est d'analyser les relations entre l'Union Européenne et Cuba sur la base d'une perspective historique-juridique. Depuis qu'en 2014 le processus de conclusion du primer lien juridique -l'Accord du Dialogue Politique et de Coopération- a été ouvert entre la Havane et Bruxelles, les deux modèles, parfois antagoniques, l'européen, de diplomatie pragmatique, et le nord-américain, d'isolement, se sont approchés d'attitudes ayant le même objectif : accélérer la transition politique du pays. Malgré leurs efforts, les autorités cubaines demeurent ancrées dans une vision traditionnelle qui pourrait fragiliser ce qui a déjà été acquis.

Mots clés: Union Européenne, Cuba, Accord du Dialogue et Coopération, États Unies.

Sumario: I. INTRODUCCIÓN. II. APROXIMACIÓN HISTÓRICA A LAS RELACIONES UE-CUBA. 1. El establecimiento de relaciones bilaterales y las primeras tensiones: 1988-1996. 2. El enfoque multilateral y la adopción de sanciones: 19972006. 3. Del diálogo político a la apertura de negociaciones del primer instrumento jurídico: 2008-2014. III. ELACUERDO DE DIÁLOGO POLIITICO Y COOPERACIÓN. 1. El análisis de las rondas de negociación. 2. Otros aspectos influyentes en el proceso de negociación del Acuerdo de Diálogo Político y Cooperación. a. El «activismo» del Parlamento Europeo y la cooperación política: «Diálogo de Alto Nivel sobre los Derechos Humanos». b. La cooperación técnica y financiera: el Programa Indicativo Multianual 2014-2020. c. La Administración de Obama y el deshielo político. IV. CONSIDERACIONES FINALES. 


\section{INTRODUCCIÓN}

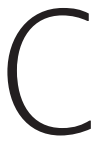

uba $^{1}$, país latinoamericano situado en el Caribe, se caracteriza por sus grandes contrastes: un índice de desarrollo humano alto según los parámetros de Naciones Unidas $(2015)^{2}$; intrínsecamente enlazado al continente europeo por factores históricos; regido durante los últimos cincuenta nueve años por un sistema político de sesgo comunista encarnado en la figura de los hermanos Castro, y sujeto a un embargo comercial, económico así como financiero desde los sesenta por su inmediato vecino, Estados Unidos (EE.UU.) es actualmente el único Estado de la región que no ha establecido ningún vínculo jurídico con la Unión Europea (UE).

Desde que en 1988 se sucedieran los primeros contactos diplomáticos, el enfoque de la UE hacia Cuba se ha visto afectado, hasta cierto punto, tanto por los intereses de los Estados miembros, especialmente de España ${ }^{3}$, como por los de EE.UU. De ahí que se afirme que la «europeización» de las relaciones haya padecido una intrínseca vulnerabilidad. Esta singularidad se aprecia especialmente al examinar la respuesta de Bruselas a los sucesivos períodos de la tensión y distención entre Washington y La Habana. A modo de ilustración, cuando en 1996 la «crisis de las avionetas» conllevó la aprobación de la controvertida Ley Helms-Burton por el legislativo norteamericano, la reacción europea, promovida activamente desde Madrid, no se hizo esperar y ahondó en la vertiente restrictiva mediante la adopción de la Posición Común (96/697/PESC) ${ }^{4}$. A pesar de lo señalado, no se ha de ignorar que, mientras EE.UU. ha optado por el aislamiento para provocar la caída del régimen castrista, Bruselas ha matizado su línea

1 Para una breve introducción sobre Cuba cfr. Roy, J., The Cuban Revolution (1959-2009): relations with Spain, the European Union, and the United States, Palgrave Macmillan, New York, 2009.

2 Véase: Informe sobre Desarrollo Humano 2015, Nota explicativa por país «Cuba». Según los datos recabados en 2014 el valor del índice de desarrollo humano (IDH) de Cuba alcanza el 0,769 , de manera que se posiciona en la categoría de desarrollo humano alto, situándolo en el puesto 67 de un total de 188 países y territorios. <http://hdr.undp.org/es/countries/profiles/ CUB>.

3 Sobre la relación España-Cuba véase: BAYO, F., «Las relaciones políticas entre España y Cuba», Documentos CIDOB, América Latina, nº 16, Barcelona, 2006, p. 16.

4 Consejo de la Unión Europea: Posición Común de 2 de diciembre de 1996 definida por el Consejo en virtud del artículo J.2 del Tratado de la Unión Europea, sobre Cuba (96/697/PESC), DOCE ${ }^{\circ}$ L 322, 12.12.96, pp. 1-2. 
de actuación por medio de gestos políticos en busca de una diplomacia pragmática, cuya manifestación más evidente se ha materializado con el cierre de las negociaciones del Acuerdo de Diálogo Político y Cooperación en marzo de 2016.

Los nuevos aires que ha infundido la Administración Obama a sus relaciones con La Habana desde finales de 2014 han desencadenado un cúmulo de acontecimientos positivos en la esfera política -reapertura de ambas embajadas y visita oficial del Presidente-, y económica -aumento del turismo norteamericano en más de un 90 por 100-. Todo ello augura un escenario favorable, que, sin embargo, se puede truncar en las próximas elecciones presidenciales norteamericanas. Además, se ha de puntualizar que solamente el Congreso, con mayoría republicana en la actualidad, posee la potestad de levantar el bloqueo, y por lo tanto, la tarea resultará cuanto menos ardua.

Hechas estas consideraciones, no se ha de omitir los esfuerzos de la UE para reivindicar su posición de impulsora de la transformación interna, tal como defendió la Alta Representante, Federica Mogherini, en Estrasburgo a mediados del presente año. En su comparecencia recalcó que, si bien marzo de 2016 había sido un mes histórico para el país -visita de Obama-, la UE no se consideraba un mero observador, sino que se hallaba plenamente involucrada en el nuevo proceso aperturista ${ }^{5}$. De todo ello se deduce que Bruselas ha pretendido conciliar su relación trasatlántica con los intereses comerciales de los Estados miembros ${ }^{6}$. De modo que los complejos acontecimientos y sus consiguientes reacciones en el marco euro-cubano exigen un análisis profundo con el fin de demostrar que, a pesar de incidir en la necesidad de una transformación del sistema político, tanto la Unión como EE.UU. han comprobado que el ostracismo no ha logrado efectividad alguna, este, en cambio, ha provocado el incremento del declive socioeconómico de los ciudadanos.

5 European Union External Action: Mogherini debates recent progress of the EU foreign policy with the Parliament: «On March 12, the High Representative concluded an historic «Political Dialogue and Cooperation Agreement» with Cuba in Havana. She briefed the Parliament on the conclusion of negotiations: «March was an historic month for Cuba, and we were there, Europe was there - not just as a bystander, but as a driving force for change». Strasbourg, 13.04.2016. <http://eeas.europa.eu/top_stories/2016/130416_ep-plenary_en.htm>.

6 Atendiendo a los datos del EUROSTAT de 2015, la UE se posiciona como el primer socio exportador de Cuba alcanzado el 23,4 por 100 del total, mientras que Canadá ostenta la segunda posición con el 17,8 por 100, y Venezuela con un 13,9 por 100 se sitúa en el tercer puesto. 


\section{APROXIMACIÓN HISTÓRICA A LAS RELACIONES UE-CUBA}

La fragilidad ${ }^{7}$ intrínseca del marco euro-cubano ha determinado su evolución. En general, se han sucedido intervalos de entendimiento mutuo, que puntualmente se han visto perjudicados por un acontecimiento o decisión gubernamental contraria a los valores defendidos por la Unión. Sin embargo, al menos se ha observado cierta coherencia por parte de esta última, dado que la ayuda humanitaria no ha sido suspendida bajo ningún precepto. Por el contrario para Cuba, toda acción dirigida a fomentar la transición política se ha interpretado como una intromisión en los asuntos internos, y por extensión como un apoyo directo al imperialismo ${ }^{8}$.

\section{El establecimiento de relaciones bilaterales y las primeras tensiones: 1988-1996}

Pese al periodo de incertidumbre que generó el triunfo de la Revolución ${ }^{9}$, algunos gobiernos europeos -Italia, Francia, Reino Unido, España y Alemania ${ }^{10}-$, no manifestaron explícitamente su rechazo a la nueva situación cubana, inclinándose incluso por anteponer sus intereses comerciales ${ }^{11}$ y económicos a posibles represalias diplomáticas. Aunque el 29 de septiembre de 1988 se considera la fecha oficial de la instauración de las relaciones euro-

7 Gratius, S., «Cuba and the European Union: a fragile relationship», Transitions, vol. 37, $\mathrm{n}^{\circ} 2$ (1996), pp. 39-50.

8 Mora Secades, A., «Las relaciones de la UE con Cuba y Estados Unidos», Revista de Estudios Europeos, vol. 20, no 65 (septiembre-diciembre 2003), pp. 3-11.

9 Moreno Fraginals, M. R., «The Cuban Revolution», International Encyclopedia of the Social \& Behavioral Sciences, $2^{\circ}$ ed., vol. 5 (2015), pp. 367-374.

10 OJeda RevaH, M., «Cuba y la Unión Europea. Una perspectiva histórica», Latinoamérica, n ${ }^{\circ} 54$ (enero-junio, 2012), pp. 9-36.

11 En el caso de España, incluso teniendo en cuenta las patentes diferencias ideológicas existentes entre ambos sistemas políticos, se convirtió en el tercer socio comercial, por detrás de la URSS y Japón, como consecuencia de la conclusión de varios acuerdos comerciales ya que de esta forma conservó el tratamiento de «nación más favorecida». Al margen de lo económico, las fricciones diplomáticas no se hicieron esperar -expropiaciones y nacionalizaciones-, siendo la de mayor trascendencia la producida en enero de 1960 durante la intervención de Fidel Castro en la televisión. En ella acusó a la sede diplomática española de prestar ayuda a los grupos de oposición, en particular a los religiosos. Ante lo cual el entonces embajador, Juan Pablo de Lojendio, irrumpió en directo para contraargumentar al interlocutor. La solución al incidente trajo consigo la expulsión del representante gubernamental, que lejos de retornar «victorioso» a Madrid, fue ignorado y rebajado a puestos administrativos de menor entidad. 
cubanas, conviene señalar que ya a mediados de la década de los setenta, Fidel Castro había señalado la importancia de entablar un acuerdo formal. Un año más tarde cayó el muro de Berlín y el mundo comenzó su transformación con el colapso de la Unión Soviética (URSS), que conllevó el fin de la Guerra Fría. Ante estos acontecimientos, se presumió que Cuba sucumbiría a corto o medio plazo, pero esta previsión no se cristalizó a pesar de la fuerte caída del PIB -35 por $100-$ y del consecuente deterioro interno ${ }^{12}$.

La primera discrepancia de calado acaeció durante el verano de 1990, cuando ciudadanos cubanos irrumpieron en las embajadas de España, Bélgica, Italia, Canadá, Suiza y la República Checa con la esperanza de que se les concediese asilo político. Hecho que provocó un incidente de gran calado conocido como la «crisis de las embajadas». Las autoridades de la isla se mostraron inflexibles llegando incluso a culpar abiertamente a los poderes públicos, especialmente a Madrid ${ }^{13}$, de colaboracionistas con el imperialismo. Esta crispada confrontación y el rápido deterioro de los derechos humanos determinaron un estancamiento de tres años en las relaciones bilaterales.

La entrada en vigor del Tratado de Maastricht y las reformas económicas instadas por Cuba destinadas a estimular la inversión extranjera en 1993, sellaron temporalmente el impasse. Como consecuencia de la relajación de las divergencias, se culminaron Acuerdos de Promoción y Protección Recíproca de Inversiones con varios Estados miembros: Italia (1993); España (1994); Reino Unido (1995); Alemania (1996), y Francia (1997) ${ }^{14}$. La firme determinación de estos países motivó que, en 1995, la Comisión Europea presentase una comu-

12 Solorza, M., «Reformas económico financieras en Cuba», Revista Problemas del Desarrollo, $\mathrm{n}^{\mathrm{o}} 185$ (47) (abril-junio, 2016), pp. 137-162.

13 Las reacciones desencadenaron declaraciones acusatorias en un clima nada constructivo, que desembocaron en la decisión de suspender los fondos de cooperación por parte del Ejecutivo español. A tenor de la nula efectividad del endurecimiento de la postura se optó a posteriori por tender puentes y adoptar una mayor flexibilidad. Dicha estrategia combinó la activa dialéctica con el ofrecimiento de asesoramiento en la persona del economista y ex ministro Carlos Solchaga, quien redactó un informe demoledor desglosando las reformas a implementar: promoción de una política de ajuste; profundización en la apertura internacional; introducción de mecanismos para alcanzar una economía de mercado; cierre de empresas no rentables o la liberalización de pequeños negocios, entre otros. Sobre el Informe Solchaga véase: Roy, J., «España y Cuba: una relación muy especial?, Revista CIDOB d'Afers Internacionals, $\mathrm{n}^{\circ} 31$ (1995), pp. 157-159.

14 Martínez Hernández, C. y Pérez Benítez, S., «Relaciones Cuba-Unión Europea (19592014) desde un enfoque histórico», Revista de Relaciones Internacionales de la UNAM, $\mathrm{n}^{\circ}$ 122-123 (abril-diciembre, 2015), p. 71. 
nicación ${ }^{15}$ abordando el futuro de las relaciones euro-cubanas. En ella se hizo especial énfasis en entablar un diálogo exploratorio inter pares tendente a articular un marco estable. En diciembre del mismo año ${ }^{16}$ los mandatarios europeos trasladaron al ejecutivo europeo la instrucción de presentar un proyecto de mandato para firmar un Acuerdo de Cooperación Económica y Comercial durante el primer semestre de 1996.

El clima de entendimiento se dinamitó a partir de la «crisis de las avionetas» ${ }^{17}$. El 24 de febrero de 1996 dos avionetas de Hermanos al Rescate procedentes de EE.UU., que se hallaban sobrevolando el espacio aéreo cubano, fueron abatidas causando bajas civiles. Este grave incidente trajo consigo la aprobación, apenas un mes después, de la discutible y cuestionable, desde los parámetros del Derecho internacional, Ley Helms-Burton ${ }^{18} \_$Cuban Liberty and Democratic Solidarity Act»-. En paralelo, se generó una gran tensión entre la UE y Cuba. En primer lugar, el Vicepresidente de la Comisión Europea, Manuel Marín, anunció la congelación del diálogo bilateral. En segundo

15 Comisión Europea: Comunicación de la Comisión al Consejo y al Parlamento Europeo. Las relaciones entre la Unión Europea y Cuba, COM(95) 306 final, Bruselas, 28.06.1995.

16 Consejo Europeo: Consejo Europeo de Madrid. Conclusiones de la Presidencia, 15-16 de diciembre de 1995, <www.europarl.europa.eu/summits/mad1_es.htm\#external>.

17 Vadillo, N., La Política Exterior de la Unión Europea hacia Cuba (1993-2003), Comunicación Social Ediciones y Publicaciones, Sevilla-Zamora, 2011, p. 85.

18 Cuban Liberty and Democratic Solidarity (Libertad) Act of 1996 (Codified in Title 22, Sections 6021-6091 of the U.S. Code) P.L. 104-114, One Hundred Fourth Congress of the United States of America, <www.treasury.gov/resource-center/sanctions/Documents/libertad.pdf>.

La Ley Helms-Burton estableció tres objetivos: el refuerzo internacional de las sanciones contra el Gobierno cubano; la asistencia a favor de la libertad e independencia de Cuba, y la protección de la propiedad de nacionales estadounidenses. Se ha de resaltar que se reconoció igualmente al Congreso la prerrogativa de finalizar el embargo, mandato que dificultaría todo margen de actuación en el supuesto de normalizar las relaciones en un futuro. Adicionalmente, en esta ocasión el instrumento jurídico elegido consagró la extraterritorialidad de sus efectos, vía iniciada en la Ley Torricelli (1992). De conformidad con lo cual se decretaron las siguientes medidas: la prohibición de préstamos, créditos o financiamiento por parte de ciudadanos o residentes de los EE.UU. en transacciones de propiedades confiscadas; el voto negativo respecto a la admisión de Cuba por el Fondo Monetario Internacional y el Banco Mundial; la autorización de demandas de ciudadanos estadounidenses a aquellos que «traficasen» con sus propiedades confiscadas, extendiendo este derecho a sujetos sin nacionalidad en el momento del agravio; y la denegación de la admisión en el país de ciudadanos extranjeros (empresarios, familiares y accionistas) que se hallasen involucrados en «traficar» con las propiedades confiscadas. HOELSCHER, C., «The Helms-Burton Bill from a European Point of View», Tilburg Foreign Law Review, vol. 6, $\mathrm{n}^{\circ} 3$ (1997), pp. 241-256. Roy, J., «La Ley Helms-Burton: desarrollo y consecuencias», Revista de Derecho Comunitario Europeo, vol. 1, nº 2 (julio-diciembre, 1997), p. 493. LÉvESQUE, P., «La saga de la loi Helms-Burton: liberté de commerce versus sécurité nationale», Les Cabiers de Droit, vol. $39, \mathrm{n}^{\circ} 4,1998$, pp. 881-923. 
lugar, durante el Consejo Europeo de Florencia ${ }^{19}$, se analizaron las circunstancias que habían motivado el bloqueo de los contactos, confiando no obstante, en que en un futuro se propiciaran, las condiciones necesarias para retomar los canales existentes. En tercer y último lugar, se europeizó la respuesta política a través de la adopción de la Posición Común (96/697/PESC) ${ }^{20}$, medio prescrito para tal fin en el TUE.

Ciertamente, la decisión de optar por este instrumento esencial estuvo orientada desde un principio a inducir la renovación del sistema político cubano, aunque en la práctica ha provocado efectos contrarios a tal ambición ${ }^{21}$. La Posición Común, fruto de la presión del Ejecutivo español ${ }^{22}$, suscitó en un principio cierto rechazo en Alemania, Bélgica, Francia, Italia, Holanda y Suecia debido a la contundencia de su contenido. Por consiguiente, Bruselas no secundó la línea dura de Madrid $^{23}$ aprobándose la versión «suavizada» con el fin de no volver a bloquear abruptamente las relaciones bilaterales. El instrumento adoleció de pragmatismo, puesto que pretendió una solución simplista y con un lenguaje vago a un escenario complejo. Dicha afirmación se extrae del contenido, dado que se precisó que no se contemplaba provocar la caída del régimen mediante la aplicación de medidas coercitivas, sino que simplemente se favorecería la transición o democratización ${ }^{24}$. El propósito del documento, vinculante para los Estados miembros, radicó en supeditar o condicionar los nexos de cooperación plena a las mejoras en lo relativo al

19 Consejo Europeo: Consejo Europeo de Florencia. Conclusiones de la Presidencia, 21-22 de junio de 1996, <www.europarl.europa.eu/summits/fir1_es.htm\#external>.

20 Consejo de la Unión Europea: Posición Común de 2 de diciembre de 1996..., op. cit.

21 Ugalde, A., «Análisis de 2012 de la Posición Común de la Unión Europea hacia Cuba: una política incoherente, contradictoria y fracasada», Revista Vasca de Sociología y Ciencia Política (IX Congreso Vasco de Sociología y Ciencia Política, Una Ciencia Social renovada para un nuevo tiempo), $\mathrm{n}^{\circ}$ 55-56 (mayo-diciembre, 2013), pp. 1591-1604.

22 Aunque durante sus años en la oposición, José María Aznar, ya exhibía abiertamente su rechazo a las actuaciones del gabinete socialista en lo referente a Cuba, desconcertó, hasta cierto punto, su decisión de introducir el elemento esencial o condicionamiento político en la cooperación al desarrollo, salvo en lo relativo a la ayuda humanitaria. Sin embargo, se ha de concretar que tal pronunciamiento se produjo en junio de 1996 a raíz de la visita del Vicepresidente de EE.UU., Al Gore, a España en los albores de la Ley Helms-Burton.

23 Tan pronto la Posición Común se concretó, el Ejecutivo cubano retiró el plácet al embajador español en La Habana.

24 Criado Alonso, F., «La política de democratización de la Unión Europea y el caso de Cuba», Revista de Estudios Políticos (nueva época), n ${ }^{\circ} 142$ (octubre-diciembre, 2008), pp. 11-41. CONTRERAS, D., «La Unión Europea ante los retos de la democratización en Cuba», Instituto Universitario de Estudios Europeos, Universidad San Pablo, Documento de Trabajo, Serie Unión Europea, $\mathrm{n}^{\circ} 35,2010$. 
«respeto de los derechos humanos y las libertades fundamentales» ${ }^{25}$. Conforme a tal objetivo se enumeraron diversas medidas ${ }^{26}$ dedicadas a facilitar el cambio. Por último, se estimó que, en la medida en que se avanzase hacia la democracia, se ampliaría el apoyo así como los medios: intensificación del diálogo político, aumento de la cooperación, llegándose incluso a la eventual exploración de posibilidades de negociar lazos jurídicos más intensos. La Posición Común se cerró con la delimitación de un seguimiento por el Consejo cada seis meses ${ }^{27}$. El Gobierno cubano se opuso frontalmente a lo dispuesto, de ahí la dureza de las declaraciones del portavoz del Ministerio de Relaciones Exteriores, Miguel Alonso, en las que manifestó que «Cuba no subordinaría su conducta ni su política exterior a las líneas marcadas por el informe de la UE» ${ }^{28}$. En cambio, EE.UU., celebró el acercamiento de posturas con su socio trasatlántico pese a que tuviesen un frente abierto respecto a la Ley Helms-Burton.

Esta confrontación permaneció durante varios meses, y ni tan siquiera las pertinentes condenas ${ }^{29}$, ni el encuentro entre el Comisario de Comercio, Leon Brittan y el Subsecretario de Comercio Internacional de EE.UU., Stuart

25 Consejo de la Unión Europea: Posición Común..., op. cit., punto 2.

26 Las medidas se pueden clasificar en diplomáticas y económicas. De un lado, las diplomáticas hallaban su fundamento en usar todos los canales posibles para intensificar el diálogo; en no dejar de reclamar responsabilidades respecto a los derechos humanos; alentar la reforma de la legislación cubana en lo referente a los derechos políticos y cívicos, y finalmente, evaluar la evolución de la política exterior e interior de la isla atendiendo a las normas que la UE aplica a otros países, especialmente enfocándose en la ratificación y cumplimiento de los convenios internacionales en materia de derechos humanos. De otro lado, las económicas, que acometerían la difícil tarea de no romper todos los contactos, de manera que la ayuda humanitaria canalizada a nivel bilateral por los Estados miembros se garantizaría a través de las organizaciones no gubernamentales, las iglesias y organizaciones internacionales, mientras que las acciones específicas de cooperación económica se mantendrían en apoyo a la apertura económica.

27 Este seguimiento se ha efectuado según los parámetros proyectados hasta junio del 2006, en el cual se anunció el siguiente Informe para finales de 2009 que no llegó a ser publicado. En los Informes siempre se ha puesto de relieve si se habían producido o no cambios que justificasen la modificación de la estrategia de la UE con respecto a Cuba. De hecho, en la décima evaluación, en diciembre de 2001, se atisbaron algunas señales positivas: mayor libertad religiosa; disminución del número de presos políticos, abandono de la pena de muerte y la ratificación de más instrumentos de NNUU sobre derechos humanos, gestos que, no obstante, se consideraban insuficientes. La parálisis incluso llegó a permitir trasladar el ejercicio de monitorización a un marco temporal anual. Sin embargo, los acontecimientos de 2003 -amplias violaciones de derechos humanos-, condujeron de nuevo al pesimismo y al reforzamiento de la validez de la Posición Común.

28 VADILLO, N., La política exterior..., op. cit., p. 90.

29 Bulletin EU n ${ }^{\circ}$ 3/1996, punto 1.4.83. Parliament resolution on Cuba. 
Eizenstat $^{30}$ modificaron los argumentos sostenidos. Por tanto, el Consejo adoptó unas conclusiones ${ }^{31}$ en las que, si bien mostraba su preocupación por la situación de los derechos humanos en la isla, manifestaba que no escatimaría esfuerzos para lograr la suspensión, al menos en lo relativo a la extraterritorialidad, de la citada norma ${ }^{32}$.

A pesar de que Washington procedió a inhabilitar el contenido polémico de la misma por un lapso de seis meses, la UE persistió en su actitud de actuar con determinación ${ }^{33}$. De un lado, y con el objeto de proteger de los efectos de la extraterritorialidad, tanto a personas físicas como jurídicas ${ }^{34}$, se aprobaron el Reglamento (CE) núm. 2271/96 35 y la Acción Común 96/668/PESC ${ }^{36}$. Ambos instrumentos fueron más allá de la controvertida norma y sumaron la Ley D'Amato, referente a Irán y Libia. En síntesis, el Reglamento prohibió el reconocimiento de la ejecución de resoluciones de juzgados o tribunales y de otras autoridades administrativas ubicados fuera de la Comunidad que hiciesen efectivos, directa o indirectamente, los textos legislativos que se enumeraban en el Anexo -Helms-Burton y D'Amato- o las acciones basadas en ellos o derivadas de ellos -art. 4-. Igualmente, ninguna persona respetaría directamente o a través de una filial o intermediario, de forma activa o por omisión deliberada, los requisitos o prohibiciones, incluidos los requerimientos o acciones de juzgados extranjeros -art. 5-. Por último, cabía la compensación si la aplicación de la normativa causase cualquier daño -art. 6-.

30 Bulletin EU no 9/1996, punto 1.4.53. Visit by Sir Leon Brittan on 3 September.

31 Bulletin EU n ${ }^{\circ}$ 7/8-1996, punto 1.4.116. Council conclusions on the Helms-Burton Act.

32 Ibid., op. cit.: «[...] a move to a WTO dispute settlement panel; changes in the procedures governing entry by representatives of US companies to EU Member States; the use/introduction of legislation within the EU to neutralize the extraterritorial effects of the US legislation; and the establishment of a watch list of US companies filing Title III actions».

33 López-JuRAdo Romero, C., «La controversia entre la Unión Europea y Estados Unidos relativa a la Ley Helms-Burton», Revista de Derecho Comunitario Europeo, vol. 1, nº 2 (julio-diciembre, 1997), pp. 581-595.

34 HubER, J., «The Helms-Burton blocking statute of the European Union», Fordham International Law Fournal, vol. 20, n 3 (March, 1997), pp. 699-716; «La réaction de l'Union européenne face aux lois américaines Helms-Burton et d'Amato», Revue du Marché Commun et de l'Union Européenne, no 408 (mai, 1997), pp. 301-308.

35 Reglamento (CE) n 2271/96 del Consejo de 22 de noviembre de 1996 relativo a la protección contra los efectos de la aplicación extraterritorial de la legislación adoptada por un tercer país, y contra las acciones basadas en ella o derivadas de ella, DO n ${ }^{\circ}$ L 309, 29.11.1996, p. 1-6.

36 Acción Común, de 22 de noviembre de 1996, adoptada por el Consejo sobre la base de los artículos J.3 y K.3 del Tratado de la Unión Europea, relativa a las medidas de protección contra los efectos de la aplicación extraterritorial de la legislación adoptada por un tercer país, y contra las acciones basadas en ella o derivadas de ella (96/668/CFSP), DO nº L 309, 29.11.1996, p. 7. 
En cambio, la Acción Común otorgó a los Estados miembros la capacidad de adoptar las medidas necesarias encaminadas a proteger a las personas -físicas o jurídicas- afectadas por la entrada en vigor de la normativa estadounidense. De otro lado, la decisión más contundente fue la presentación del correspondiente expediente en el seno de la OMC en $1997^{37}$, ante lo cual EE.UU. replicó que dicha organización no se hallaba facultada para conocer de la controversia, debido a que el fundamento jurídico se basaba en la seguridad nacional ${ }^{38}$. El asunto finalmente no se dilucidó en dicha sede porque, tras trece meses de su entrada en vigor, se obtuvo un principio de acuerdo entre Bruselas y Washington, basado principalmente en la suspensión indefinida de su parte más controvertida ${ }^{39}$. La contraprestación para el gabinete de Clinton pasó por dar una mayor visibilidad a una colaboración más estrecha en favor de una democratización del país. Indudablemente, en medio de la incertidumbre por la aplicación de la Ley Helms-Burton, la UE decidió endurecer su postura frente a Cuba, por tanto, el desacuerdo no se basaba en la exigencia de una transición política, sino en defender los intereses económicos de empresas europeas en contraposición a la arbitrariedad del legislativo de EE.UU.

\section{El enfoque multilateral y la adopción de sanciones: 1997-2006}

Las consecuencias del enfriamiento se prolongaron hasta enero de 1998, fecha en la que se produjo la histórica visita del Papa, Juan Pablo II, durante la cual se posibilitó la liberación de un grupo de presos políticos ${ }^{40}$. La eventual apertura de Fidel Castro se plasmó en la solicitud oficial para que el país fue-

37 Martínez GutiÉRrez, E., «La Unión Europea y la Ley Helms-Burton: apuntes sobre un conflicto de nuestro tiempo», Noticias de la Unión Europea, nº 174 (1999), pp. 119-132.

38 Sobre los fundamentos jurídicos de la demanda véase: SpanogLe, J. A. Jr., «Can Helms-Burton be challenged under WTO?», Stetson Law Review, vol. XXVII (1998), pp. 1313-1340.

39 Bulletin EU n ${ }^{\circ}$ 4/1997, punto 1.4.90. Council conclusions on the Helms-Burton and D'Amato Acts.

40 Bulletin EU 1/2-1998, Cuba, punto 1.4.17: The following presidency statement on behalf of the European Union on the release of prisoners in Cuba was published in Brussels, London and Havana on 24 February. «The European Union appreciates the welcome extended by Cuba to Pope John Paul and views this as a positive step in the development of religious freedom there. The Union also welcomes the Cuban Government decision to release immediately a certain number of prisoners in response to the Pope's appeal, and urges the authorities to liberate and fully reintegrate into society all who have been imprisoned because of peaceful expression of their political views, including the four leading members of the internal dissidence working group. The Union considers both the visit and the release of prisoners as positive steps towards greater religious and civic freedom in Cuba, and looks for this process to continue». 
se considerado observador en las negociaciones del instrumento sustituto de Lomé. En otros términos, se dieron los primeros pasos para su inclusión en el grupo de países de África, Caribe y Pacífico -ACP_41. Ello desencadenó un clima propenso para retomar los contactos ${ }^{42}$, no obstante, la Posición Común aún continuaría de iure guiando la actuación europea. La positiva acogida de los países $\mathrm{ACP}^{43}$ permitió que, ya en otoño del mismo año, Cuba participase como observador. Por primera vez, las relaciones euro-cubanas parecían encaminarse hacia un marco regional, aspecto de innegable valor que superaría el impasse padecido con anterioridad. Si bien se cursó la petición para obtener el estatus de miembro de pleno derecho en marzo de 2000, cuya aceptación se comunicó en diciembre del mismo año por el Consejo de Ministros de los Estados ACP, finalmente no fructificó su pertenencia al Acuerdo de Cotonou -sucesor de Lomé-. Las razones versaron en el empeoramiento de los derechos humanos -detención de disidentes; juicios sumarios y condena a muerte de varios activistas-, que supuso la condena tanto europea ${ }^{44}$ como internacional ${ }^{45}$.

La relajación de la fricción llegó con la presidencia belga de 2001 en concreto a raíz de una visita de la Troika a La Habana ${ }^{46}$. Las partes acordaron

41 Llorca Rodríguez, C.M. y Cuenca García, E., «Las relaciones comerciales de la UE con el Grupo ACP», ICE: Revista de Economía, nº 824 (2005), pp. 173-190.

42 Bulletin EU 10-1998, punto 1.3.118. El 2 de octubre de 1998 el Ministro de Comercio cubano, Ricardo Cabrisas Ruiz, visitó Bruselas reuniéndose con el Comisario de Comercio, Pinheiro, para tratar asuntos relativos a la petición de Cuba de acudir a las negociaciones del sucesor de Lomé en calidad de observador. Empero, el Comisario europeo reiteró la posición de la UE en lo relativo a un mayor entendimiento sobre la importancia de los derechos humanos, la democracia y una economía de libre mercado.

43 Puerta Rodríguez, H., «El Acuerdo de Cotonú y el posible ingreso de Cuba», Revista de Estudios Europeos, ${ }^{\circ} 60$ (enero-abril, 2002), pp. 3-24.

44 La preocupación europea se recogió en una declaración de la Presidencia de la UE sobre Cuba de 25 de junio de 1999, la cual instó al Gobierno cubano a adherirse al Pacto Internacional sobre los Derechos Civiles y Políticos. <http://data.consilium.europa.eu/doc/document/ST-94081999-INIT/es/pdf .

Además, de la revisión semestral de la Posición Común, la UE se mantuvo realmente activa durante 1999 expresando su inquietud por el rápido deterioro interno en el campo de los derechos humanos. Así lo estimó el Parlamento Europeo en su resolución del 11 de marzo, o las consecutivas declaraciones de la Presidencia el 16 de marzo y el 25 de junio, respectivamente.

45 Comisión de Derechos Humanos: Resolución de la Comisión de Derechos Humanos 1999/8 Derechos humanos en Cuba, 50ª sesión, 23.04.1999. Aunque el año anterior no se dictase la tradicional resolución condenando la situación de los derechos humanos en la isla, en 1999 frente a un panorama diferente, sí expresó su preocupación por «la continuada violación de los derechos humanos y libertades fundamentales».

46 Bulletin EU 12-2001, punto 1.6.112. Meeting between the European Troika and Mr Felipe Perez Roque, Cuban Minister of Foreign Affairs, in Havana on 1 and 2 December. 
involucrarse en mayor grado, en lo relativo a los derechos humanos encauzando un diálogo político de carácter regular. Asimismo recalcaron, por un lado, su rechazo a la imposición de normas unilaterales con efecto extraterritorial en contra de los principios básicos del derecho internacional, y, por otro, condenaron el terrorismo en todas sus formas ${ }^{47}$. Una vez más, la «luna de miel» permitía avances de consideración: el nombramiento del Jefe de Misión de Cuba ante la UE (2002), la presentación por Cuba de su petición de adhesión al Convenio Cotonou (enero 2003) ${ }^{48}$, la participación como observador en todos los foros ACP-UE (febrero 2003) ${ }^{49}$, y la apertura de una oficina de la Comisión Europea en La Habana (marzo 2003) $)^{50}$.

El panorama, sin embargo, volvió a ensombrecerse a causa de la detención de setenta y cinco disidentes además de la ejecución sumaria de tres secuestradores $^{51}$. La reacción de Bruselas fue bastante inesperada, pues a las medidas tradicionales ${ }^{52}$ y a la posposición indefinida de manifestarse sobre la candidatura cubana a la adhesión de Cotonou, se le sumó la implantación de una serie de sanciones unilaterales a partir del verano de $2003^{53}$ : limitar las visitas gubernamentales bilaterales de alto nivel; reducir el nivel de la participación de los Estados miembros en acontecimientos culturales; invitar a los

47 Esta referencia al terrorismo se asume dentro del contexto de la sociedad internacional de 2001 y los atentados terroristas de las Torres Gemelas y el Pentágono. Inclusive Cuba el 4 de octubre decidió acceder a todas las convenciones de NNUU en materia de terrorismo.

48 The Secretaries of the ACP-EC Council of Ministers, Request by the Republic of Cuba to accede to the ACP-EC Partnership Agreement, ACP-CE 214/03, Brussels, 24.01.2003. <http:// data.consilium.europa.eu/doc/document/ST-2104-2003-INIT/en/pdfs.

49 Copy of a Letter H.E. Mr Felipe Perez Roque, Minister for Foreign Affairs of the Republic of Cuba, Request by the Republic of Cuba for observer status in the framework of the ACP-EC Partnership Agreement, ACP-CE 2108/03, Brussels, 14.02.2003. <http://data.consilium.europa.eu/doc/document/ST-2108-2003-INIT/en/pdf>.

50 Bulletin EU 3/2003 punto 1.6.11. Visit by Mr Nielson to Cuba from 9 to 14 March. «On this first official visit to Cuba Mr Nielson saw the President, Mr Fidel Castro, and many public figures including Mr Felipe Pérez Roque, the Foreign Minister, and Mr Oswaldo Payá Sardiña, winner of the Sakharov Prize in 2002. Mr Nielson opened the Commission's delegation office in Havana and visited several cooperation projects financed by the European Union. Discussions with Cuban officials centered on Cuba's recent application to accede to the ACP-EU partnership agreement signed in Cotonou, the conditions to be met if the country is to accede, development cooperation and trade relations between the European Union and Cuba».

51 Díez Lezcano, E., «La crisis del 2003 y el futuro de las relaciones Unión Europea-Cuba», Revista de Estudios Europeos, $\mathrm{n}^{\circ} 69$ (enero-abril, 2005).

52 Declaraciones de la Presidencia 7735/03 (Presse 93), 26.03.2003; Resolución del Parlamento Europeo sobre los derechos humanos en Cuba, P5_TA(2003)0191, 10.04.2003 y Resolución del Parlamento Europeo sobre Cuba, P5_TA (2003)0374.

53 Bulletin EU 6-2003 punto 1.6.25. 
disidentes cubanos a las celebraciones de fiestas nacionales; y volver a examinar la Posición Común de la UE.

Las observaciones de los dirigentes cubanos calificadas por la UE como sumamente ofensivas, degeneraron aún más la situación, y en las conclusiones del Consejo de junio ${ }^{54}$ se consideró inaceptable el comportamiento de las autoridades cubanas. Sin embargo, la espiral de hostilidad alcanzó su zenit cuando Fidel Castro, con ocasión de la conmemoración anual del asalto al Cuartel Moncada, pronunció un discurso de una línea ideológica dura a la vez que provocadora ${ }^{55}$. En él no solamente arremetió contra la UE por su doble moral y su falta de independencia, sino que igualmente anunció la renuncia de cualquier ayuda o resto de ayuda humanitaria que pudiese ofrecer la Comisión Europea o los Estados miembros ${ }^{56}$.

En efecto, el deterioro, que se observaba a nivel bilateral y multilateral, se materializó en la denominada «guerra de los canapés» consistente en la in-

54 Bulletin EU 6-2003 punto 1.6.126. «Recalling its concern about the deterioration of the human rights situation in Cuba, the Council considered the behaviour of the Cuban authorities towards the European Union, its Member States and the acceding States unacceptable [...]».

55 Discurso pronunciado por el Comandante en Jefe Fidel Castro Ruz, Presidente de la República de Cuba, en el acto por el aniversario 50 del asalto a los cuarteles Moncada y Carlos Manuel de Céspedes, efectuado en Santiago de Cuba, el 26 de julio del 2003. Extractos de la intervención: «[...] Hace varias semanas, a principios de junio, la Unión Europea aprobó una infame resolución, elaborada por un grupito de burócratas, sin análisis previo de los propios Ministros de Relaciones Exteriores, e impulsada por un personaje de estirpe e ideología fascistas: José María Aznar. La misma constituyó un acto cobarde y repugnante, que se sumaba a la hostilidad, las amenazas y peligros que implica para Cuba la política agresiva de la superpotencia hegemónica. Decidieron suprimir o disminuir al mínimo lo que califican de «ayuda humanitaria» a Cuba. [...] El gobierno de Cuba, por elemental sentido de dignidad, renuncia a cualquier ayuda o resto de ayuda humanitaria que pueda ofrecer la Comisión y los gobiernos de la Unión Europea. Nuestro país sólo aceptaría este tipo de ayuda, por modesta que fuese, de las autonomías regionales o locales, de las Organizaciones No Gubernamentales y movimientos de solidaridad, que no imponen a Cuba condicionamientos políticos. [...]», <www.cuba.cu/gobierno/discursos/2003/esp/f260703e.html>.

56 En lo relativo a España, el Gobierno adoptó medidas cercanas a los postulados de George W. Bush, con lo cual Castro incluyó acusaciones de terrorismo de Estado contra José María Aznar y su predecesor, Felipe González, para después, continuar sus descalificaciones en una marcha frente a la embajada española en La Habana, y en una intervención televisiva, llamándole, entre otros improperios «führercito, de ideas nazi-fascistas» y recalcando que inclusive Franco fue más astuto. La Moncloa no entró en la espiral de exabruptos y aseguró que las inversiones españolas no peligraban. Empero, el Presidente español cerró su ciclo político con un discurso ante el Congreso de EE.UU. donde aludió a Cuba explicitando su deseo de que pronto fuese bienvenida a la comunidad de naciones libres. Véase: El País: «Castro arremete contra Aznar y González y recuerda los crímenes del GAL», 27.04.2003. <http://elpais.com/ diario/2003/04/27/espana/1051394409_850215.html> El País: Castro lidera una marcha contra Aznar frente a la Embajada española», 12.06.2003. <http://internacional.elpais.com/internacional/2003/06/12/actualidad/1055368805_850215.html>. 
vitación de disidentes a las fiestas nacionales o la participación de funcionarios europeos en las actividades organizadas por este colectivo. Sin embargo, a mediados de 2004, el Gobierno cubano liberó a varios opositores, acción acogida por la UE como un gesto positivo ${ }^{57}$. En definitiva, a pesar de encontrarse en vigor las sanciones o de las reticencias de algunos Estados miembros -Alemania y Suecia-, las relaciones no se habían interrumpido totalmente.

Los escollos no empezaron a superarse hasta enero 2005 con motivo de la suspensión temporal durante seis meses de todas las medidas adoptadas dos años antes ${ }^{58}$. En junio del mismo año se mantuvo dicha decisión, pese a que el contexto interno no había variado significativamente ${ }^{59}$. De modo que se puede afirmar que la UE abandonó la vía restrictiva, pero el Parlamento Europeo sostuvo su posición de resaltar el escaso progreso hacia una democracia pluralista mediante preguntas puntuales de europarlamentarios de grupos de signo diferente así como de la concesión del Premio Sájarov al colectivo de las Damas de Blanco ${ }^{60}$. El fracaso del método de aislamiento precipitó que los años consecutivos se destinaran a entablar un nuevo acercamiento como consecuencia de dos acontecimientos relevantes: el traspaso temporal, tras cuarenta ocho años, de poderes de Fidel Castro a su hermano Raúl Castro, y la reconciliación hispano-cubana ${ }^{61}$. En consecuencia, la

57 Declaración de la Presidencia en nombre de la Unión Europea sobre la liberación de opositores políticos en Cuba, 11438/04 (Presse 227), Bruselas, 15.07.2004.

58 Consejo de la Unión Europea: Conclusiones del Consejo sobre Cuba, Bruselas, 31.01.2005: «[...] Se suspenderán temporalmente todas las medidas adoptadas el 5 de junio de 2003. [...] El Consejo decide que las medidas antes citadas se reexaminen antes de julio de 2005, a la luz de la evolución hacia el pluralismo y el respeto de los derechos humanos en Cuba».

59 Informes de Human Rights Watch y Amnistía Internacional publicados en 2005, <www.hrw.org/ legacy/wr2k5/pdf/cuba.pdf>; <www.es.amnesty.org/en-que-estamos/noticias/noticia/articulo/71presos-de-conciencia-siguen-encarcelados-en-cuba-por-expresar-sus-ideas/>.

60 El Parlamento Europeo concede anualmente el premio Sájarov a personas que han contribuido de manera excepcional a la lucha por los derechos humanos en todo el mundo llamando de esta forma la atención sobre las violaciones de estos. Las Damas de Blanco no han sido las únicas galardonas de nacionalidad cubana tanto en 2002, Osvaldo Payá Sardiñas, como en 2010, Guillermo Fariñas, recibieron sendos reconocimientos.

${ }^{61}$ García PÉrez, R., «España y la definición de la política europea hacia Cuba», en CARdONA Llorens, J.; Pueyo Losa, J.; Rodríguez-Villasante y Prieto, J. L. y Sobrino Heredia, J. M. (eds.); AZnar GómeZ, M. (coord.), Estudios de Derechos Internacional y Derecho Europeo en Homenaje al Profesor Manuel Pérez González, Tomo II, Tirant lo Blanch, Valencia, 2012, p. 1960. La proyección exterior de España se modificó con la llegada a la Moncloa de Rodríguez Zapatero, dado que se desligó de los parámetros norteamericanos suscitando divergencias entre ambas administraciones. Como consecuencia de tal decisión gubernamental, se reemprendió su influencia bilateral, que había decrecido a favor de Venezuela y China. En primer lugar, buscó alternativas para disminuir los efectos de las sanciones unilaterales de la UE, de manera que estableció meca- 
UE se hallaba dispuesta a reanudar el diálogo político, eso sí, sin abandonar los cauces destinados a intercambiar impresiones con la oposición al régimen.

\section{Del diálogo político a la apertura de negociaciones del primer instrumento jurídico: 2008-2014}

A finales de febrero de 2008, Raúl Castro fue elegido Presidente por la Asamblea Nacional del Poder Popular para un mandato de cinco años ${ }^{62}$. En su discurso ${ }^{63}$ de investidura manifestó que el sistema político no se alteraría, de manera que despejó la incógnita de una transición hacia una democracia, porque «el país ya vivía en ella» ${ }^{64}$. Unos días más tarde el Comisario de De-

nismos de entendimiento con los opositores diferenciados del vínculo oficial. En segundo lugar, cuando en verano de 2004 se excarcelaron presos políticos, el Ejecutivo español insistió en Bruselas que se había de reflexionar sobre la efectividad de la dimensión restrictiva. En tercer y último lugar, El ministro de Asuntos Exteriores y Cooperación, Miguel Ángel Moratinos, declaró ante la Comisión de Asuntos Exteriores del Congreso de los Diputados un decálogo respecto a la política exterior española. En el cual -punto octavo-, proclamó lo siguiente: «[...] se apoyará el proceso de reformas abierto en Cuba, a través del respeto mutuo y el diálogo constructivo».

62 Roy, J., «Cuba: transición, sucesión, estabilidad, seguridad», América Latina Hoy, nº 52 (2009), pp. 15-39.

63 Discurso pronunciado por el compañero Raúl Castro Ruz, Presidente de los Consejos de Estado y de Ministros, en las conclusiones de la sesión constitutiva de la VII Legislatura de la Asamblea Nacional del Poder Popular. Palacio de las Convenciones, La Habana, 24 de febrero de 2008, «Año 50 de la Revolución»: «[...] Muchas expectativas se generaron, tanto en Cuba como en el extranjero, en torno a la integración del Consejo de Estado que acaba de elegir la Asamblea. La fundamental fue despejada por el compañero Fidel en su Mensaje del 18 de febrero. Poco puedo agregar a lo expresado por él, salvo reconocerle a nuestro pueblo, en nombre de la Dirección de la Revolución, las innumerables muestras de serenidad, madurez, confianza en sí mismo y la combinación de genuinos sentimientos de tristeza y firmeza revolucionaria. Asumo la responsabilidad que se me encomienda con la convicción de que, como he afirmado muchas veces, el Comandante en Jefe de la Revolución Cubana es uno solo. Fidel es Fidel, todos lo sabemos bien. Fidel es insustituible y el pueblo continuará su obra cuando ya no esté físicamente. Aunque siempre lo estarán sus ideas, que han hecho posible levantar el bastión de dignidad y justicia que nuestro país representa. Sólo el Partido Comunista, garantía segura de la unidad de la nación cubana, puede ser digno heredero de la confianza depositada por el pueblo en su líder. Es la fuerza dirigente superior de la sociedad y el Estado y así lo establece el artículo 5 de nuestra Constitución, aprobada en referendo por exactamente el 97,7\% de los votantes. [...]». $<$ http://cuba.cu/gobierno/rauldiscursos/2008/esp/r240208e.html>.

64 Ibid., op. cit.: «[...] Y añadí que si el pueblo está firmemente cohesionado en torno a un único partido, este tiene que ser más democrático que ningún otro, y con él la sociedad en su conjunto, que desde luego, como toda obra humana, se puede perfeccionar, pero sin dudas es justa y en ella todos tienen oportunidad de expresar sus criterios, y más importante aún, de trabajar para hacer realidad lo que en cada caso acordemos. [...]». 
sarrollo y Ayuda Humanitaria, Louis Michel, viajó a La Habana con el objetivo de normalizar las relaciones bilaterales ${ }^{65}$, de ahí la importancia de su encuentro con el Ministro de Asuntos Exteriores cubano para evidenciar el reciente acercamiento. El abandono del paradigma limitante se efectuó con el levantamiento de las sanciones en el Consejo de junio del mismo año de $2008^{66}$. Sin embargo, no se modificó ni un ápice la Posición Común, que aún mantendría su validez ${ }^{67}$. El relanzamiento oficial de la cooperación se escenificó con un nuevo traslado a la isla del Comisario, Louis Michel, durante el cual se firmó una declaración conjunta estableciendo que el monto destinado a esta ascendería a 20-25 millones de euros. Asimismo, se acordaron las bases para el diálogo político de alto nivel de carácter incondicional, recíproco y no discriminatorio atendiendo tanto a la igualdad soberana de los Estados como al principio de no injerencia en los asuntos internos.

El siguiente avance se plasmó en la adopción del Informe Estratégico de País 2011-20013 ${ }^{68}$, que armó un marco para la distribución de la ayuda financiera. La metodología de este instrumento se caracteriza por el estudio de la condición política y económica del destinatario por parte de la Comisión Europea. En relación al análisis de la situación política, el traspaso de poderes entre los hermanos Castro no había acarreado una transición per se, sino solamente una «actualización» del proyecto con un nuevo periodo de reformas socioeconómicas en sí un tanto modestas de las que destacaron ${ }^{69}$ : la entrega en usufructo de tierras estatales para su explotación y el despido masivo de empleados estatales ${ }^{70}$. De modo que los sectores prioritarios identificados por la UE no comprendieron lo político, sino que se circunscribieron únicamente a áreas más técnicas: seguridad alimentaria -10 millones de euros-; medioambiente y adaptación al cambio climático -7 millones

65 European Commission: Commissioner Michel encouraged by positive talks with Cuban government, IP/08/409, Brussels, 07.03.2008. <http://europa.eu/rapid/press-release_IP-08-409_ en.htm?locale=en>.

66 Consejo de la Unión Europea, Conclusiones sobre Cuba, 11076/08, Bruselas, 23.06.2008.

67 Bayo, F. y Gratius, S., «La UE reabre una nueva etapa en sus relaciones con Cuba», Opinión América Latina, Centro de Estudios y Documentación Internacionales de Barcelona, 10.07.2008.

68 Republic of Cuba-European Union, Country Strategy Paper and National Indicative Programme for the period 2011-2013.

69 Mesa-Lago, C., «Las reformas de Raúl Castro y el Congreso del Partido Comunista de Cuba: avances, obstáculos y resultados», Documentos CIDOB, América Latina, $\mathrm{n}^{\circ} 35$ (diciembre, 2011).

70 En 1990 el empleo estatal representaba el 95 por 100 del total, por el contrario en 2000 había decrecido hasta un 77 por 100, aunque, en el momento de redactar el Informe Estratégico de País había aumentado a un 80 por 100 . 
de euros-; estudios, formación e intercambio de expertos -3 millones de euros-.

Ciertamente, el hecho de haber determinado los sectores de cooperación con La Habana tan sólo un par de días después de una resolución ${ }^{71}$ del Parlamento Europeo, en la cual se condenó «enérgicamente» la muerte del disidente político Orlando Zapata Tamayo tras una huelga de hambre y el deterioro de los derechos humanos en la isla, ya ponía de manifiesto que no se tomarían medidas restrictivas al menos de inmediato. Particularmente, la Alta Representante, Catherine Ashton, exteriorizó su preocupación, y se refirió a las reuniones de diálogo político, que se venían celebrando dos veces al año desde 2008, como el foro adecuado para debatir el asunto. A su vez se ha de enfatizar que durante el primer semestre de 2010, España ostentó la presidencia del Consejo, en cuya agenda de trabajo incluyó la modificación de la Posición Común ${ }^{72}$, pero, a raíz de los acontecimientos descritos en el párrafo anterior, no se alcanzó tal anhelo ${ }^{73}$. No obstante, la actuación española no quedó totalmente desdibujada ya que se anunció la excarcelación de cincuenta y dos prisioneros políticos tras negociones con la Iglesia Católica y de los esfuerzos del Ministro de Exteriores español, Miguel Ángel Moratinos.

Ya en octubre de 2010, los ministros de Exteriores de los Estados miembros encargaron a la Alta Representante que explorase las posibilidades de elevar jurídicamente el plano de las relaciones con $\mathrm{Cuba}^{74}$. Conforme a lo cual en noviembre de 2012, el Consejo cambió impresiones decidiendo mantener futuros debates en torno a esta cuestión ${ }^{75}$. En línea con el nuevo panorama, en enero de 2014, el Ministro de Asuntos Exteriores neerlandés, Frans Timmermans, con ocasión de su visita oficial a La Habana, proclamó que Cuba estaba cambiando, razón por la cual la UE debería estar presente a través de conver-

71 Parlamento Europeo, Resolución del Parlamento Europeo, de 11 de marzo de 2010, sobre la situación de los presos políticos y de conciencia en Cuba, P7_TA(2010=0063), Estrasburgo, 11.03.2010.

72 PÉREZ-STABLE, M., «Europe might take another step back», Inter-American Dialogue, 11.02.2010. $<$ http://archive.thedialogue.org/page.cfm?pageID=32\&pubID=2254\&mode=print>.

73 El Mundo: «Zapatero: 'La UE debe adoptar una postura exigente respecto a Cuba'», 08.01.2010, <www.elmundo.es/elmundo/2010/01/08/espana/1262941560.html>.

74 Consejo de la Unión Europea: Comunicado de Prensa, sesión n ${ }^{\circ} 3041$ del Consejo, Asuntos Exteriores, Luxemburgo, 25.10.2010. Presse 286.

75 Consejo de la Unión Europea: Comunicado de Prensa, sesión no 3199 del Consejo, Asuntos Exteriores, Bruselas, 19.11.2012. Presse 467. 
saciones directas con las autoridades pertinentes ${ }^{76}$. El Ministro estuvo muy acertado en su intervención, porque unos días después, el entonces Presidente de la Comisión Europea, Durão Barroso, admitió que se estaba discutiendo revisar la Posición Común 77 .

Los gestos se aceleraron y a finales de ese mismo mes $^{78}$, se produjo una circunstancia histórica: el Consejo aprobó abrir la negociación de un Acuerdo de Diálogo Político y Cooperación. En febrero, Catherine Ashton hizo pública $^{79}$ su confianza en consolidar el compromiso con Cuba, a la vez que puntualizaba que dicha decisión no constituía un cambio paradigma respecto al pasado -derechos humanos-. El contraparte de exteriores cubano, Bruno Rodríguez, anunció la aceptación de la nueva propuesta, que venía a significar el fin de las políticas unilaterales sobre Cuba, reiterando en su discurso que el país actuaría en el proceso de una manera constructiva, para concluir condenando el bloqueo de EE.UU. que, en su opinión, además de causar violaciones de derechos humanos, afectaba gravemente a la economía incurriendo en un «genocidio» ${ }^{80}$. Finalmente, en abril de 2014 se abrió la primera ronda de negociaciones sobre el futuro Acuerdo de Diálogo Político y Cooperación. A pesar de encontrarnos ante un evento trascendental, la mayoría de los ejecutivos de los Estados miembros se mantuvieron cautos, salvo las autoridades neerlandesas, francesas y portuguesas que exhibieron su satisfacción ${ }^{81}$.

76 Government of the Netherlands, Timmermans encourages Cuba to undertake further reforms, 07.01.2014, <www.government.nl/latest/news/2014/01/07/timmermans-encourages-cuba-to-undertake-further-reforms $>$.

77 Leogrande, W. M., «Relaxing the EU's Common Position on Cuba would allow Europe to play a more active role in shaping the country's development», <http://blogs.lse.ac.uk/europpblog/2014/01/28/relaxing-the-eus-common-position-on-cuba-would-allow-europe-to-playa-more-active-role-in-shaping-the-countrys-development/s.

78 Consejo de la Unión Europea: Decisión del Consejo por la que se autoriza a la Comisión y a la Alta Representante de la Unión para Asuntos Exteriores y Política de Seguridad a abrir negociaciones, en nombre de la Unión Europea, sobre las disposiciones, que son competencia de la Unión, de un Acuerdo de Diálogo Político y Cooperación entre la Unión Europea y sus Estados miembros, por una parte, y la República de Cuba, por otra, PES 1449, RELEX 1091, 17116/13, Bruselas, 28 de enero de 2014.

79 CONSEjo DE LA UnIÓN EUROPEa: El Consejo adopta directrices de negociación para un diálogo político bilateral y un Acuerdo de Cooperación con Cuba, Bruselas, 10.02.2014, Presse 60.

80 Ministerio de Relaciones ExTERIores de Cuba: Temas abordados por el Ministro de Relaciones Exteriores de Cuba, Bruno Rodríguez Parrilla, en conferencia de prensa ofrecida el jueves, 6 de marzo de 2014, en la sede de la Cancillería cubana, 07.03.2014. <www.minrex.gob.cu/es/temasabordados-por-el-ministro-de-relaciones-exteriores-de-cuba-bruno-rodriguez-parrilla-en>.

81 European Parliamentary Research Service: «A new phase in EU-Cuba relations», At a glance, 23.06.2014, p. 2. 
En efecto, el inicio de las negociaciones promovió una nueva fase ${ }^{82}$ en el nexo euro-cubano encaminada a instituir el primer instrumento jurídico ${ }^{83}$. No obstante, esta no estuvo exenta de contrariedades, que a modo de ilustración se resumirían en los siguientes extremos: cláusula de derechos humanos; transición a una economía de libre mercado o al menos la seguridad jurídica hacia las acciones de los nacionales de los Estados miembros, así como otras relativas a la consecución del Acuerdo dado su posible polémico debate en el seno del Parlamento Europeo, el cual es bien conocido por su apoyo a los disidentes políticos. En definitiva, a priori, el proceso de negociación no se apreciaba libre de dificultades, sino todo lo contrario, cada ronda constituiría un reto.

\section{El Acuerdo de Diálogo Político y CoOperación}

En la diplomacia tradicional las negociaciones de acuerdos internacionales se enfocan desde la más absoluta confidencialidad a fin de desvincular polémicas externas del resultado final. Sin embargo, desde que los ciudadanos demandan una mayor transparencia en el proceso de regularización de materias sensibles, se ha generado una conciencia de la importancia de conocer qué se está discutiendo y cómo les afectará en el caso de adoptarse tal instrumento. De modo que la UE ha intentado conjugar esta demanda con la necesidad de salvaguardar sus intereses proporcionando información sobre el estado del affaire mediante un comunicado de prensa tras cada ronda de negociación completada entre 2014 y 2016. Ahora bien, debido a las escasas indicaciones, es interesante no sólo analizar las preguntas provenientes del Parlamento Europeo, sino, igualmente, aproximarse a otros elementos -diálogo político y Programa Indicativo Multianual 2014-2020-, o al deshielo político instado por la Administración Obama para obtener una visión completa del documento adoptado en marzo de 2016.

\section{El análisis de las rondas de negociación}

Según las directrices aprobadas, el futuro Acuerdo cubriría los siguientes pilares: diálogo político, cooperación y diálogo político, y por último, comer-

82 Gratius, S., «Engaging Cuba», European Institute for Security Studies, February 2014.

83 Alzugaray Treto, C., «Una nueva etapa en las relaciones entre Cuba y la Unión Europea», Iberoamericana, vol. XV, $\mathrm{n}^{\circ} 57$ (2015), pp. 168-172. 
cio. En torno a ellos se han celebrado siete rondas de negociación. La primera de ellas se efectuó a finales de abril de $2014^{84}$, en La Habana ${ }^{85}$. En ese encuentro, las partes establecieron las directrices que dirigirían las conversaciones. De igual modo, se alcanzó un compromiso respecto a la estructura general, lo que contribuyó a que se revelaran las primeras impresiones sobre el contenido. Tal como se decidió en la reunión, la segunda ronda se trasladó a Bruselas en verano del mismo año ${ }^{86}$. El intercambio se centró primordialmente en la cooperación, en cambio las cuestiones políticas e institucionales no se abordaron en esa convocatoria. En lo referente al comercio, la UE introdujo el capítulo que habría de atender a los objetivos conjuntos, sin ignorar la normativa $\mathrm{y}$ los principios que rigen el comercio internacional.

La sesión que tenía que sucederse en diciembre en la capital cubana, se retrasó hasta marzo de $2015^{87}$. Tras este preocupante paréntesis de siete meses, las discusiones se retomaron en una atmósfera constructiva aprobándose varios artículos. No obstante, estas también permitieron identificar elementos de divergencia en aspectos conectados a la cooperación: el papel de la sociedad civil, la transposición de las obligaciones jurídicas internacionales, y las diferencias de los sistemas jurídicos, en especial, en lo concerniente a los derechos humanos. Por otra parte, se aprovechó igualmente para explorar las opiniones en torno a los dos capítulos principales del Acuerdo: el diálogo político y comercio.

La cuarta ronda se llevó a cabo, según lo previsto, en junio de $2015^{88}$ aprovechando la presencia de las contrapartes en la Cumbre UE-CELAC. El capítulo de cooperación y de diálogo sobre políticas sufrió progresos sustanciales, llegándose a cerrar la mayor parte de su contenido. La misma coyuntura se dio

84 Note-1st round of negotiations between the EU and Cuba 29-30 April 2014.

<http://collections.internetmemory.org/haeu/content/20160313172652/http://eeas.europa.eu/ delegations/cuba/documents/press_corner/20140429_1ra_ronda_de_negociaciones_entre_la_ union_europea_y_cuba_29-30_de_abril_2014_en.pdf>.

85 Las rondas de negociación se han ido alternando entre en ambas capitales.

86 Second round of EU-Cuba negotiations towards a bilateral Political Dialogue and Cooperation Agreement. <https://eeas.europa.eu/sites/eeas/files/20140828_press_lines_en_1.pdf>.

87 Third round of EU-Cuba negotiations towards a bilateral Political Dialogue and Cooperation Agreement in Havana. <https://eeas.europa.eu/sites/eeas/files/20150305_press_lines_3rdround_ negotiations_en_1.pdf>

88 Fourth round of negotiations towards a EU-Cuba Political Dialogue and Cooperation Agreement, Brussels, 15 and 16 June 2016. <http://collections.internetmemory.org/haeu/ content/20160313172652/http://eeas.europa.eu/delegations/cuba/documents/press_corner/20150616_4throundofnegotiations.pdf>. 
en lo relativo al comercio, ya que se constató que «prácticamente» se había ultimado. En esta ocasión, el capítulo de diálogo político, fue en el que se emprendió la exploración de las posiciones debido a la dificultad que estas podrían implicar en el desarrollo del proceso. Teniendo en cuenta el nivel de entendimiento existente, se contempló las posibilidades de acelerar el procedimiento para concluir las negociaciones tan pronto como fuese posible. En esta línea se manifestaron el Ministro de Relaciones Exteriores cubano, Bruno Rodríguez, y la Alta Representante, Federica Mogherini, tanto en La Habana ${ }^{89}$ como en Bruselas $^{90}$.

La quinta ronda se celebró en septiembre de $2015^{91}$. La fluidez que se daba en lo comercial, contrastaba con las diferencias forjadas en la cooperación y al diálogo -la cuestión de la migración, la protección consular y el apoyo a los operadores económicos...-, razón por la cual se emplazaron estos puntos a futuras reuniones. En lo referente al diálogo político, se verificaron en detalle los textos propuestos, intentándose acercar las posiciones, pues de esta manera, se moderarían las divergencias mediante el trabajo técnico complementario antes de la sexta sesión. Esta se desarrolló a fines del mismo año ${ }^{92}$

89 Remarks by High Representative/Vice-President Federica Mogherini following her visit to Cuba, 150325_04_en, Havana, 25.03.2015: «[...] We decided today to speed up the rhythm of our negotiations - hopefully to manage to finalise the framework of our dialogue and agreement by the end of this year. As relations between the European Union and Cuba are strong, histori$\mathrm{cal}-$ it is 25 years of diplomatic relations in itself between the EU and the country. Most of the European Union Member States have bilateral agreements or arrangements. So we definitely have a lot on which we can build and we believe that finalising this agreement will be key to develop our political dialogue and our cooperation on more solid basis».

<http://collections.internetmemory.org/haeu/content/20160313172652/http://eeas.europa.eu/ statements-eeas/2015/150325_04_en.htm>.

90 Remarks by the High Representative and Vice-president Federica Mogherini at the press conference with Cuban Minister for Foreign Affairs, Bruno Rodríguez, 150422_03, Brussels, 22.04.2015: $\ll[\ldots]$ As it comes to our bilateral relations, as you know, we are negotiating a political dialogue and cooperation agreement. We had the chance of discussing this already when I was visiting Havana, where we expressed our willingness to strengthen and intensify our relations also by accelerating our negotiation process. We agreed on having the next round of negotiations in June and to have it followed by other rounds so that we can try to finalise the agreement by the end of the year».

$<$ http://eeas.europa.eu/delegations/cuba/3401/remarks-by-the-high-representative-and-vicepresident-federica-mogherini-at-the-press-conference-with-cuban-minister-for-foreign-affairs-bruno-rodriguez-parilla_en>.

91 Fifth round of EU-Cuba negotiations towards a bilateral Political Dialogue and Cooperation Agreement in Havana.

<http://collections.internetmemory.org/haeu/content/20160313172652/http://eeas.europa.eu/ delegations/cuba/documents/press_corner/20150910_press_lines_5thround_negotiations.pdf>

92 Sixth round of EU-Cuba negotiations towards a bilateral Political Dialogue and Cooperation Agreement in Brussels. <https://eeas.europa.eu/sites/eeas/files/20151202_notadeprensa_vi_ ronda_union_europea_en_0.pdf $>$. 
en Bruselas. En ella se logró finalizar el capítulo de comercio y cooperación comercial constatándose que el capítulo de cooperación y de diálogo sobre políticas se encontraba en una fase muy adelantada. En cambio, a pesar de los importantes progresos habidos en el diálogo político, aún se necesitarían conversaciones adicionales en busca de una mayor convergencia. En otro orden de materias, se empezaron a intercambiar posiciones sobre las disposiciones institucionales, finales, y el preámbulo. Estas continuaron siendo objeto de discusión en la séptima ronda, que constituyó la última, fijándose para la primavera de $2016^{93}$.

Indudablemente, la negociación se ha realizado con gran rapidez ${ }^{94}$, puesto que el 11 de marzo de 2016, días antes de la histórica visita del Presidente Obama, Federica Mogherini y Bruno Rodríguez concluyeron el texto en Cuba, dando lugar al cierre de esta fase. En una comparecencia conjunta ${ }^{95}$ ambos representantes manifestaron su satisfacción por los resultados. La Alta Representante, proclamó que la firma del Acuerdo marcaría el final de la Posición Común de 1996, en línea con lo cual, declaró que propondría una decisión del Consejo para abrogar formalmente dicho documento. Su homólogo cubano, recalcó que había sido un proceso dinámico, riguroso aunque no exento de complejidades subrayando, sin embargo, el éxito del proceso manifestando que la UE «es y seguirá siendo crecientemente un socio importante para Cuba» ${ }^{96}$.

Desde ese momento, el texto ha quedado sometido a los respectivos trámites internos, razón por la cual el contenido no se hará público hasta la adopción de la propuesta por la Comisión Europea. En línea con lo cual, el Conse-

93 En esta ocasión no se publicó comunicado de prensa tras su celebración.

94 Gratius, S., «Lecciones del Acuerdo Cuba-UE», Opinión, CIDOB, n 393, marzo, 2016. ZoNDI, S., «The implications of the Cuba-EU Agreement on enhanced political dialogue and cooperation», Global Insight, Institute for Global Dialogue, issue 126, April, 2016.

95 Declaración Conjunta en ocasión de la inicialización del Acuerdo de Diálogo Político y Cooperación Cuba-UE, 160311_01, La Habana. <https://eeas.europa.eu/headquarters/headquartershomepage/5456/declaracin-conjunta-en-ocasin-de-la-inicializacin-del-acuerdo-de-dilogo-poltico-y-cooperacin-cuba-ue_es>.

Mogherini a la rueda de prensa conjunta con el Ministro de Asuntos Exteriores de Cuba, Bruno Rodríguez, en La Habana, 160311_02, La Habana. <https://eeas.europa.eu/delegations/ cuba/9533/mogherini-a-la-rueda-de-prensa-conjunta-con-el-ministro-de-asuntos-exterioresde-cuba-bruno-rodrguez-en-la-havana-_es>.

96 Granma: «Este Acuerdo es un paso sin precedentes en la historia de los vínculos entre la Unión Europea y Cuba», La Habana, 11.03.2016, <www.granma.cu/mundo/2016-03-11/este-acuerdo-es-un-paso-sin-precedentes-en-la-historia-de-los-vinculos-entre-la-union-europea-y-cuba-11-03-2016-23-03-34>. 
jo de Asuntos Exteriores de julio, concluyó que el objetivo de la UE es firmar el Acuerdo antes de finalizar el presente año ${ }^{97}$. Un nuevo impulso se produjo en dicha dirección, cuando el 22 de septiembre de 2016, la Comisión Europea propuso al Consejo respaldar el Acuerdo así como revocar la Posición Común adoptada hace veinte años ${ }^{98}$. El Consejo revisará en los próximos meses ambas propuestas, observándose una voluntad decida para acelerar los plazos y de esta forma cumplir con lo establecido.

\section{Otros aspectos influyentes en el proceso de negociación del Acuerdo de Diálogo Político y Cooperación}

a) El «activismo» del Parlamento Europeo y la cooperación política: «Diálogo de Alto Nivel sobre los Derechos Humanos»

Tal como expresó el Ministro de Asuntos Exteriores cubano en la ceremonia de inicialización, el proceso no estuvo exento de complejidades. Estas no se agotaron con las discrepancias entre las partes, sino que también en el seno del Parlamento Europeo, tradicionalmente menos condescendiente que otras instituciones, se hizo patente la variedad de criterios sobre cómo reconducir las relaciones euro-cubanas. Por ende, y a fin de obtener una visión exhaustiva del marco de las negociaciones, proponemos realizar un análisis pormenorizado de las preguntas más incisivas que posibilitaron percibir detalles no anticipados por las autoridades competentes.

Para su estudio, las veinte y tres preguntas trasladas durante el proceso de negociación, se han clasificado en siete categorías: tratamiento de los derechos humanos; imposición de condiciones previas; implicación de la sociedad civil; déficit de transparencia; revocación de la Posición Común; cuestiones comerciales; y finalmente, la posición de EE.UU. Indiscutiblemente se puede apreciar que entre algunas de ellas existe cierto grado de correspondencia. En lo relativo al tratamiento de los derechos humanos ${ }^{99}$, los europarlamentarios

97 Council of the European Union: Outcome of the Council Meeting, $3482^{\text {nd }}$ Council meeting, Foreign Affairs, 11355/16, Brussels, 18.07.2016.

98 European Commission: The European Commission has adopted the proposal to the Council on the signing of the Political Dialogue and Cooperation Agreement (PDCA) with Cuba, IP/16/3133, Brussels, 22.09.2016. <http://europa.eu/rapid/press-release_IP-16-3133_en.htm>.

99 Sergio Paolo Francesco Silvestris (PPE), $\mathrm{n}^{\circ}$ E-001610-14, 13.02.2014. Fernando Maura Barandiarán (ALDE), nº E-006495-14, 02.09.2014, <www.europarl.europa.eu/plenary/en/parliamentary-questions.html>. 
han interpelado a la Comisión Europea sobre las medidas que se propondrían conducentes a asegurar el respeto de estos. La respuesta manifestó que, sin lugar a dudas, el Acuerdo incluiría este elemento esencial ${ }^{100}$, además de una estructura para institucionalizar el diálogo político y la cooperación. A partir de lo cual se deduce que los vínculos quedarán sujetos al modelo europeo de la condicionalidad tal como se insertó por ejemplo en los Acuerdos de Asociación Euromediterránea ${ }^{101}$.

En lo relativo a la imposición de medidas previas se anhelaba que la UE ligase los progresos de las conversaciones y la posterior ratificación a sustanciales cambios políticos, en particular, los miembros de $\mathrm{ALDE}^{102}$ pretendieron que se optase por la metodología carrot o «más por más», a través de la cual los avances se asocian a la evolución interna y a la reacción del ejecutivo del país en cuestión. Específicamente se incorporaron aquellos exigidos por el movimiento «Sociedad Civil Cubana», que se resumían en el fin de la represión política. Por supuesto, la respuesta desechó la utilidad de interponer unas condiciones previas, dado que el Acuerdo no sería un objetivo político en sí mismo, sino un instrumento de promoción de los intereses y valores de la UE respecto a Cuba.

La implicación de la sociedad civil, tema complejo, fue introducido por el hecho de que las negociaciones se circunscribieron únicamente a los canales gubernamentales, razón por la cual, los europarlamentarios quisieron conocer el papel desempeñado por dicho sector ${ }^{103}$. La Comisión Europea contestó que la UE seguía manteniendo los contactos regulares con dicho colectivo, por lo que conocía sus preocupaciones y expectativas, el cual se hallaba informado en

\footnotetext{
100 Según el artículo 2 de los Acuerdos de Asociación Euromediterránea, dicho «elemento esencial» se incorpora de la siguiente manera: «el respeto de los principios democráticos y de los derechos humanos fundamentales, tal y como se enuncia en la Declaración Universal de Derechos Humanos, inspira las políticas internas e internacionales de las Partes y constituye un elemento esencial del presente acuerdo». De modo que en el Acuerdo de Diálogo Político y Cooperación se podría determinar un tratamiento similar.

${ }^{101}$ Soroeta Liceras, J., «La condicionalidad política en los Tratados internacionales entre la UE y los Estados del Mediterráneo Meridional» en QUEL LóPEZ, J. (dir.) y Bollo AROCENA, M. D. (coord.), Intereses públicos, intereses privados, su defensa y colisión en el Derecho Internacional, Thomson Reuters-Aranzadi, Navarra, 2013, pp. 171-202.

102 Fernando Maura Barandiarán (ALDE), nº E-009088-14, 12.11.2014. Fernando Maura Barandiarán y Pavel Telicka (ALDE) n ${ }^{\circ}$ P-003749-15, 06.03.2015. Fernando Maura Barandiarán y Pavel Telicka (ALDE), n ${ }^{\circ}$ E-oo6072-15, 16.04.2015.

${ }^{103}$ Ilhan Kynchyuk (ALDE), no E-003062-15, 27.02.2015. Miroslav Poche (S\&D), nº E-015348$15,02.12 .2015$.
} 
todo momento de la evolución de las conversaciones. Esta inquietud alrededor de la falta de debate crítico está estrechamente conectada con el déficit de transparencia ${ }^{104}$, que ha sido el núcleo de la última consulta en lo concerniente al objeto de estudio. A ello se refirió el argumento del Servicio de Acción Exterior para negarse a hacer público el texto que hubiera podido minar el curso de las negociaciones y dañar los lazos bilaterales, a pesar de lo cual el Ombudsman Europeo se opuso. Aunque todavía no se ha procedido a contestar ${ }^{105}$, se puede anticipar que la Comisión Europea se ceñirá a los tiempos de espera según el procedimiento establecido en los Tratados.

Otro punto discutido a lo largo de esos meses fue la revocación de la Posición Común ${ }^{106}$, y no solamente a través de las preguntas, sino también en el debate de julio de 2015 sobre Cuba ${ }^{107}$. Los miembros del Parlamento Europeo han manifestado reiteradamente la conveniencia de retirar la Posición Común, cuando se ha optado por una política más pragmática. La réplica fue que esta no había planteado problemas, aunque más tarde se afirmó que el Acuerdo la daría por finalizada. En lo referente a lo comercial interpuso una interpelación interesante sobre la posibilidad de culminar en el futuro un Acuerdo de Libre Comercio $^{108}$. Posibilidad que se ha contemplado, puesto que la Parte IV sobre Comercio y Cooperación en Comercio ha insertado una cláusula de revisión a favor de profundizar los lazos bilaterales.

Finalmente, el proceso de aceleración del acercamiento La HabanaWashington acabó influyendo en el desarrollo de las relaciones euro-cubanas, ya fuesen comerciales, regionales o simplemente en lo relativo a la cooperación europea con EE.UU. con el fin de aunar esfuerzos ${ }^{109}$. La Comisión Europea adujo que daba la bienvenida a los avances para un mayor acercamiento cubano-norteamericano pero que eso no influía en sus decisiones. En resumen, y de acuerdo con los Tratados, el Parlamento Europeo habrá de aprobar

\footnotetext{
${ }^{104}$ Lars Adaktusson (PPE), $\mathrm{n}^{\circ} \mathrm{E}-006500-16,31.08 .2016$.

105 En el momento de cerrar el presente trabajo, fines de septiembre de 2016, la pregunta no había sido todavía contestada por parte de la Comisión Europea.

${ }^{106}$ Grupo GUE/NGL， no E-005697-15, 09.04.2015. Joâo Pimenta Lopes (GUE/NGL), $\mathrm{n}^{\circ} \mathrm{E}-002877-16,08.04 .2016$.

107 Parlamento Europeo: Futuras relaciones UE-Cuba (debate), Estrasburgo, 08.04.2015, $<$ www.europarl.europa.eu/sides/getDoc.do? pubRef=-//EP//TEXT+CRE+20150708+ITEM$011+\mathrm{DOC}+\mathrm{XML}+\mathrm{V} 0 / / \mathrm{ES}>$.

108 Sorin Moisa (S\&D), $\mathrm{n}^{\circ}$ E-004378-16, 31.05.2016.

${ }^{109}$ István Vjhelyi (S\&D), nº E-005785-15, 10.04.2015. Gabriel Mato y Carlos Iturgaiz (PPE), $\mathrm{n}^{\mathrm{o}} \mathrm{E}-006494-15,22.04 .2015$. Jarostaw Walesa (PPE), n ${ }^{\circ} \mathrm{E}-011418-15,16.07 .2015$. Neeva Gill $(\mathrm{S} \& \mathrm{D}), \mathrm{n}^{\mathrm{o}} \mathrm{E}-011680-15,21.07 .2015$.
} 
el texto, y entonces veremos cómo interactuaran las distintas posturas de los grupos. Eso sí, teniendo en cuenta los antecedentes, el debate será arduo, dividido entre los defensores de los valores -democracia-, y los partidarios de los intereses -comercio-, respectivamente.

Un elemento de debilidad estructural de las relaciones euro-cubanas ha sido la situación de los derechos humanos en la isla, de ahí que el Diálogo de Alto Nivel, haya sido considerado un gran logro por las partes. En junio de 2015 se celebró el primer encuentro ${ }^{110}$, en el cual se concretaron las modalidades así como los objetivos a perseguir aunque también se trataron asuntos de interés mutuo -bilaterales o regionales-, y materias de carácter sectorial -género, derechos del niño, libertad de expresión y asociación...-. La reunión puso de manifiesto el compromiso de Cuba y la UE por continuar intensificando el apoyo en lo concerniente a los derechos humanos mediante la construcción de la confianza. Ya en $2016^{111}$, se llevó a cabo la segunda sesión de esta modalidad de diálogo en consonancia con la propuesta de realizarlo anualmente. En esta ocasión, se discutieron cuestiones de mayor complejidad evocando principalmente la implicación de la sociedad civil en la esfera pública. Todavía es pronto para exigir resultados visibles, aunque no se ha de descartar la posibilidad de que a través de este canal se podría complementar el futuro Acuerdo en la medida en que en su seno se discutiesen elementos más discordantes erigiéndose la UE mediador entre las distintas facciones políticas de la isla.

b) La cooperación técnica y financiera: el Programa Indicativo Multianual 2014-2020

Desde que en 2008 se reanudó la cooperación para el desarrollo se han financiado más de ochenta proyectos en Cuba, alcanzando hasta 2013 un monto de unos 85 millones de euros en total ${ }^{112}$. Por tanto, esta línea de trabajo se

110 EUROPEAN UNION EXTERNAL ACTION: First EU-Cuba high level human rights dialogue meeting on 25th June, 150625_06, Brussels, 25.06.2015. <https://eeas.europa.eu/headquarters/headquarters-homepage/6333/first-eu-cuba-high-level-human-rights-dialogue-meeting-on-25th-june_en>.

111 EUROPEAN UNION EXTERNAL ACTION: EU-Cuba Human Rights Dialogue in Havana, 160608_03, 08.06.2016. <https://eeas.europa.eu/headquarters/headquarters-homepage/5024/eu-cuba-human-rights-dialogue-in-havana_en>.

112 Delegación de la UE en Cuba: <https://eeas.europa.eu/delegations/cuba/651/proyectos-en-cuba_es>. 
ha beneficiado aún más si cabe a raíz de la firma del Programa Indicativo Multianual 2014-2020 $0^{113}$. En él se estipularon tres sectores en los que se concentrarían los esfuerzos bilaterales: agricultura sostenible y seguridad alimentaria; medioambiente: mejor uso de los recursos naturales para el desarrollo sostenible; y apoyo a la modernización socioeconómica sostenible. En primer lugar, se destinaron 21 millones de euros para el sector agroalimentario, cuyo objetivo fundamental buscaba contribuir al desarrollo del país mediante un aumento de la productividad, y promocionando las pequeñas cooperativas. Cuba soporta un gran lastre en este vector, dado que importa la mayoría de los productos de subsistencia básica, lo cual genera un desequilibrio considerable, no solo a nivel de la población -éxodo rural-, sino también de sostenibilidad -uso racional de los recursos naturales-.

En segundo lugar, el sector del medioambiente obtuvo 18 millones de euros enfocados a cuestiones del agua y a los retos respecto a la adopción de medidas destinadas a lucha contra el cambio climático. La deteriorada red de suministro de agua provoca un pérdida del 60 por 100, a lo que hay que añadirle la falta de reciclaje y la contaminación que agravan la situación. Hasta la actualidad se han implementado proyectos piloto financiados por la UE a través de cauces bilaterales o temáticos, sobre todo en la agricultura, de modo que se aprovecharan las «buenas prácticas» para perfeccionar la cooperación bilateral. En último lugar, se destinaron 10 millones de euros al tercer sector. Este ha constatado desde 2008 diversas transformaciones a causa de la política interna, aunque igualmente ha sufrido los embates de la crisis mundial. En consecuencia, la labor de la UE giraría a favor de garantizar el éxito de las medidas de las autoridades cubanas: expansión de la iniciativa privada, inversión extranjera y modernización de la administración pública entre otros. Adicionalmente, se distribuyó un millón de euros para medidas de apoyo destinadas a alcanzar los objetivos fijados: estudios de impacto, promoción de la coordinación entre los diferentes donantes...

En la actualidad, hay dieciocho proyectos en curso $^{114}$, entre los que cabría destacar, «AGROCADENAS - Programa de Apoyo al Fortalecimiento

113 Multiannual Indicative Programme (MIP) for Cuba 2014-2020. <https://ec.europa.eu/europeaid/sites/devco/files/mip-cuba-2014-2020_en.pdf>.

114 Delegación de la UE en Cuba: La temática de estos proyectos cubre la seguridad alimentaria, medioambiente enfocado en energías renovables, cultura-patrimonio, social, fortalecimiento de la capacidad de gestión, e intercambio de expertos. <https://eeas.europa.eu/sites/eeas/files/ongoing_projects_cuba_agosto2016.pdf>. 
de Cadenas Agroalimentarias a nivel local» cofinanciado por NNUU, cuya finalidad es mejorar el funcionamiento de los sectores de la leche, la carne, el maíz y el frijol, así como reforzar las capacidades de los agricultores, cooperativas y otras entidades no-estatales. En definitiva, ambas partes han fijado su posición en el tema de la cooperación al desarrollo en sendos documentos que permitirán afianzar el Acuerdo de Diálogo Político y Cooperación.

La cooperación técnica y financiera no se circunscribe únicamente a lo bilateral pues Cuba también participa en programas regionales de la UE para América Latina: Al-Invest -permite la internacionalización de las PYMES-; COPOLAD -colaboración en materia de políticas sobre drogas-; EUROCLIMA -mitigación de los efectos del cambio climático-, y Erasmus+-movilidad educativa-. Finalmente, la Dirección General de la Comisión Europea para la Ayuda Humanitaria y Protección Civil (ECHO) ha otorgado 3 millones de euros a seis proyectos dirigidos a reducir el riesgo de los desastres naturales, que provocan grandes destrozos materiales en cada temporada de huracanes.

Este campo de trabajo se muestra relativamente ambicioso, aunque procede hacer notar que al centrarse en aspectos secundarios y de carácter más bien técnico no incorpora a grupos externos al círculo gubernamental. Quizás el próximo Programa Indicativo vaya más allá ampliando los elementos a cuestiones de calado político: modernización de la administración, reforma de leyes penales y civiles o mayor presencia de otras sensibilidades en su redacción.

\section{c) La Administración de Obama y el deshielo político}

La historia común de estos vecinos se retrotrae hasta la Guerra de Independencia de EE.UU. No obstante, el punto de inflexión se produjo cuando Washington se involucró en el conflicto hispano-cubano de finales del siglo XIX tras la voladura del buque Maine ${ }^{115}$ convirtiéndose en un asunto hispano-estadounidense. El Tratado de Paris ${ }^{116}$ dio por finalizada la contienda, pero incoó la ocupación de la isla de iure desde un principio, inclusive cuando

115 RUEDA, G., «El «desastre» del 98 y la actitud norteamericana», Anales de la Historia Contemporánea, $\mathrm{n}^{\circ} 14$ (1998) (publicado en marzo de 1999), pp. 77-93.

116 Tratado de paz entre España y los Estados Unidos de América, firmado en Paris el 10 de diciembre de 1898, art. 1.: «España renuncia todo derecho de soberanía y propiedad sobre Cuba. En atención a que dicha isla, cuando sea evacuado por España, va a ser ocupada por los Estados Unidos, los Estados Unidos, mientras dure su ocupación, tomarán sobre si y cumplirán las obligaciones que por el hecho de ocuparla, les impone el Derecho Internacional, para la protección de vidas y haciendas». 
se aprobó su Constitución de 1902 -Enmienda Platt ${ }^{117}$-. El golpe de Estado en la década de los treinta, encabezado por Fulgencio Batista, gozó de la simpatía norteamericana hasta que la represión y el subdesarrollo económico y social propiciaron el triunfo de la Revolución. Frente a la atenta mirada de la sociedad internacional, Washington reconoció al nuevo Ejecutivo cubano. Ahora bien, nada hizo presagiar entonces que, en pocos meses, la relación bilateral se deterioraría vertiginosamente hasta su abrupta su interrupción a raíz de la nacionalización y expropiación tanto de latifundios -Ley de Reforma Agrariacomo de todos los negocios extranjeros, mayoritariamente estadounidenses, en el verano de 1960. Pese al ofrecimiento de compensaciones, estas se consideraron inadecuadas por parte de los afectados. La reacción de EE.UU. fue especialmente contundente porque impuso un embargo económico, excepto en medicamentos y productos alimentarios, a partir de octubre de ese año.

Las fricciones alcanzaron un nuevo momento álgido con la fallida invasión de Bahía de Cochinos en abril (1961), orquestada por la CIA ${ }^{118}$, cuya consecuencia directa radicó en la declaración de Fidel Castro de adoptar los lineamientos marxista-leninista bajo los auspicios de Moscú y Beijín. Tan solo un año después de este suceso, el mundo volvió a asomarse al abismo a raíz de la «crisis de los misiles». A lo largo de los años, las diferentes administraciones norteamericanas han ido profundizando el embargo dificultando las posibilidades de normalizar las relaciones bilaterales. De todo ello proviene la expectación generada, cuando, en abril de 2009, Obama anunció, durante la V Cumbre de las Américas, que se comprometía a buscar una nueva relación con $\mathrm{Cuba}^{119}$.

${ }^{117}$ En la Constitución cubana de 1902 se incluyó la Enmienda Platt, la cual menguó la soberanía de la joven nación, al quedar supeditada al control expreso de EE.UU. Particularmente llamativo fue su artículo 3: «que el Gobierno de Cuba consiente que los Estados Unidos puedan ejercitar el derecho de intervenir para la conservación de la Independencia cubana, el mantenimiento de un Gobierno adecuado para la protección de vidas, propiedad y libertad individual y para cumplir las obligaciones que con respecto a Cuba han sido impuestas a los Estados Unidos por el tratado de París y que deben ahora ser asumidas y cumplidas por el Gobierno de Cuba». Por consiguiente, se promulgó un pseudo protectorado solamente el Presidente Franklin D. Roosevelt dio por finalizado en 1934 en base a la política de «buen vecino».

118 Dunne, M., «Perfect failure: the USA, Cuba and the Bay of Pigs, 1961», The Political Quaterly, vol. 82, n 3 (July-September, 2011), pp. 448-458.

119 Powell Solares, C., «La política exterior y de seguridad de Barack Obama: ¿hacia un nuevo paradigma geopolítico estadounidense?», Real Instituto Elcano, Documento de Trabajo 20/2015, p. 211. Del Pino GutiÉrrez, D., «Estados Unidos y Cuba. Obama da el primer paso», Política Exterior, vol. 23, n 129 (2009), pp. 25-28. 
El eco de sus palabras se proyectó en septiembre de ese mismo año cuando se declaró el levantamiento de las restricciones de viajes familiares y de envíos de remesas. Sin embargo, estos esfuerzos se recompensaron de una forma bastante negativa por parte cubana con la detención del ciudadano Alan Gross, acusado de crímenes contra el Estado. Esta fricción no desalentó al nuevo inquilino de la Casa Blanca para culminar su ambición, dado que, en 2011, se restauraron los permisos de viaje para estadounidenses por razones culturales e intercambios académicos incrementándose de esta forma los contactos entre la sociedad civil. En contraposición, Raúl Castro ejecutó un movimiento histórico, la reforma migratoria ${ }^{120}$ en términos bastantes aperturistas: eliminación de la carta de invitación, expedición de pasaportes a conocidos disidentes, entre otras. En resumen, las limitadas concesiones acompañadas de la excarcelación de Alan Gross y de espías cubanos por las respectivas autoridades, condujeron a contactos diplomáticos secretos facilitados por el Vaticano y Canadá, que cristalizaron en el anuncio simultáneo por los Presidentes Obama ${ }^{121}$ y Castro ${ }^{122}$ del inicio de las conversaciones con el fin de normalizar las relaciones bilaterales. Las declaraciones del 17 de diciembre de 2014, breves pero de gran valor simbólico, hicieron patente la voluntad de acabar con este significativo anacronismo ${ }^{123}$. La

${ }^{120}$ Los intermitentes impasses entre Cuba y EE.UU. se han ido tradicionalmente intercalando con continuas oleadas de migración cubana huyendo del régimen, que se ha ido asentando desde los sesenta mayoritariamente en Miami, conformándose un lobby en el exilio de marcado carácter republicano. El episodio de mayor cobertura mediática de los últimos años lo protagonizó el rescate de un menor de edad, Elián González, en 1999, en contra de la política pies mojados/pies secos del Gobierno estadounidense. La historia copó portadas desembocando en una cuestión política a las puertas de las elecciones presidenciales norteamericanas del año 2000. Razón por la cual, e incluso en contra de la posición del lobby cubano, las autoridades estadounidenses apoyaron la reunificación con sus familiares cubanos llegando a usar la fuerza. A partir de lo cual se adoptó un acuerdo por el que se autorizó la compra de alimentos y medicamentos siempre que su pago se hiciese en efectivo para paliar los efectos del bloqueo.

121 The White House: Statement by the President on Cuba Policy Changes, 17.12.2014: [...] In the most significant changes in our policy in more than fifty years, we will end an outdated approach that, for decades, has failed to advance our interests, and instead we will begin to normalize relations between our two countries», <www.whitehouse.gov/the-press-office/2014/12/17/statement-president-cuba-policy-changes $>$.

122 Alocución del Presidente Cubano, 17.12.2014: «[...] Desde mi elección como Presidente de los Consejos de Estado y de Ministros, he reiterado en múltiples ocasiones, nuestra disposición a sostener con el gobierno de los Estados Unidos un diálogo respetuoso, basado en la igualdad soberana, para tratar los más diversos temas de forma recíproca, sin menoscabo a la independencia nacional y la autodeterminación de nuestro pueblo», <www.cuba.cu/gobierno/rauldiscursos/2014/esp/r171214e.html>.

123 Sobre la cuestión del restablecimiento de las relaciones bilaterales, véase, LEOGRANDE, W., «Cuba, EE UU, y el deshielo de 50 años de relaciones hemisféricas», Política Exterior, vol. 28, 
reacción europea no se hizo esperar con un comunicado de la Alta Representante ${ }^{124}$, que comenzaba de una manera muy gráfica que «hoy ha empezado a caer otro muro». Acertadamente hizo hincapié en la victoria del diálogo frente a la confrontación, pues desde 2008 la propia UE había promocionado tal metodología con resultados no ciertamente espectaculares pero que constituía un cauce de entendimiento bilateral progresivo.

Aunque el anuncio televisado generó enormes expectativas, no evidenció un cambio por parte de las autoridades cubanas de su discurso tradicional. A propósito de lo cual, Raúl Castro desgranó sus demandas previas en la III Cumbre de Estados Latinoamericanos y del Caribe (CELAC), que obviamente partían de la eliminación del embargo ${ }^{125}$, poniendo de nuevo de manifiesto la falta de confianza en las verdaderas intenciones de las autoridades norteamericanas. Se discierne de esta forma un doble juego en la orientación ideológica del régimen, sobre todo de la vieja retaguardia, con la necesidad del país de incorporarse a la sociedad internacional máxime cuando su principal sponsor, Venezuela, se halla sumido en una crisis socioeconómica sin precedentes.

En otros términos, se han conjugado gestos políticos como el encuentro en privado de ambos Presidentes en la VII Cumbre de las Américas de 2015 en Panamá, o la trascendental, crucial e histórica visita de Obama a la isla en marzo de $2016^{126}$, con un diálogo regular ${ }^{127}$ además de otros de carácter sectorial -migración, narcotráfico, medioambiente-. Tan pronto como el furor se calmó la diplomacia cubana y norteamericana se apresuró a cristalizar los compromisos asumidos por sus líderes. Hasta la fecha, los logros más significativos celebrados por Bruselas, han sido la supresión de Cuba de la lista

\footnotetext{
$\mathrm{n}^{\circ} 165$ (mayo-junio, 2015), pp. 124-132. «Normalizing US-Cuba relations: escaping to shackles of the past», International Affairs, vol. 91, nº 3, 2015, pp. 473-488. GUADARRAMa DomíNGUEZ, R., «Cuba y Estados Unidos: el largo proceso de reconocimiento», Latinoamérica. Revista de Estudios Latinoamericanos, vol. 60 (mayo, 2015), pp. 53-92. HoffmanN, B., «Cuba en la «era pos-17D», Iberoamericana, vol. 15, n ${ }^{\circ} 57$ (2015), pp. 159-161.

124 European Union External Action: Statement of the High Representative and Vice President Federica Mogherini on US-Cuba relations, 141217_07, Brussels, 17.12.2014. <http:// collections.internetmemory.org/haeu/content/20160313172652/http://eeas.europa.eu/statements-eeas/2014/141217_03_en.htm>.

125 Powell Solares, C., «La política exterior...», op. cit., p. 26.

126 El País: «Obama llega a Cuba para sellar el deshielo con Castro», 21.03.2016. <http://internacional.elpais.com/internacional/2016/03/20/actualidad/1458456684_965374.html>.

127 Hasta el momento se han celebrado tres rondas octubre de 2015, febrero y julio de 2016.
} 
del Departamento de Estado respecto a países promotores del terrorismo ${ }^{128}$, y la apertura en las capitales de sus respectivas embajadas ${ }^{129}$. Asimismo, otras medidas han relajado el embargo, que solamente puede ser levantado por el Congreso y no por orden ejecutiva, así como el uso de tarjetas de crédito y débito de turistas estadounidenses, la facilitación de transacciones bancarias, etc. ${ }^{130}$.

En resumen, se puede afirmar que el multilateralismo acompañado de un nuevo enfoque hacia América Latina de la Administración Obama, tiene su máxima expresión en el deshielo hacia Cuba. No obstante, los más de cincuenta años de embargo no han provocado el desgaste de los principios marxistas-leninistas, ya que el Partido Comunista no ha desistido en repetir que los males cubanos son producto de este «genocidio económico». Asimismo, también es evidente que Raúl Castro no ha simplificado el proceso con la adopción de reformas de gran calado, pues solamente ha optado por acciones «cosméticas» ${ }^{131}$. Por consiguiente, la lentitud y la fragilidad marcarán este ciclo con el riesgo de terminar abruptamente apenas se celebren las elecciones presidenciales en noviembre de 2016, cuyos candidatos mantienen dos visiones diametralmente opuestas ${ }^{132}$. Donald Trump, por su parte, en un principio amparó la normalización, pero después matizó sus palabras anunciando su intención de revertir la política demócrata, a pesar de las recientes acusaciones provenientes de la prensa de violar el embargo ${ }^{133}$. Por otra parte, la candidata demócrata, Hillary Clinton, ha defendido en Miami la necesidad de continuar con el enfoque «inteligente» alentando al sector privado, a

128 U.S. Department of State: Rescission of Cuba as a State Sponsor of Terrorism, Washington DC, 29.05.2015. <www.state.gov/r/pa/prs/ps/2015/05/242986.htm>.

129 EUROPEAN UNION EXTERnal ACTION: Statement of Spokesperson on US-Cuba relation, 150701_03, Brussels, 01.07.2015, <https://eeas.europa.eu/delegations/cuba/6326/statementof-the-spokesperson-on-us-cuba-relations_en>.

130 U.S. Department of the Treasury, Office of Foreign Assets Control, Cuban Assets Control Regulations, January 15, 2015, <https://www.treasury.gov/press-center/press-releases/pages/j19740. aspx>.

131 Mesa-Lago, C., «El lento avance de la reforma en Cuba», Política Exterior, vol. 30, n 171, mayo-junio, 2016, pp. 94-104.

132 Council on Foreign Relations: Campaign 2016. The candidates and the world: Cuba. <www.cfr. org/campaign2016/>.

${ }^{133}$ LeE Anderson, J., «Donald Trump's Cuba Hypocrisy», The New Yorker, 01.10.2016, <www. newyorker.com/news/news-desk/donald-trumps-cuba-hypocrisy>. La prensa norteamericana ha difundido la «hipocresía» de Donald Trump respecto a Cuba, ya que, según su investigación, este ignoró el embargo al abonar una determinada cantidad -68.551,88 dólares- a consultores por su labor indagando sobre la posibilidad de establecer negocios en la isla. 
la sociedad civil y a los propios estadounidenses de origen cubano a ejercer una mayor presión al régimen cubano para que inicie una verdadera reforma política y económica en el país.

\section{Consideraciones Finales}

Todos los elementos que han sido objeto de estudio en el presente trabajo han ido matizando las relaciones euro-cubanas a lo largo del periodo analizado. De conformidad con tal aserción se desprende que ni la diplomacia pragmática -método europeo-, ni el aislamiento -método estadounidense-, han propiciado una auténtica transición democrática en Cuba. Sin embargo, es evidente que frente a la coyuntura internacional actual es necesario terminar con esta situación anacrónica. Tanto la UE como EE.UU. iniciaron un viraje en su política hacia la isla encaminado a tender puentes para que en el momento en que se produzca el ansiado cambio, ambos actores se hallen facultados para erigirse en interlocutores privilegiados.

El proceso no será fácil, todo lo contrario, ya que estará plagado de dificultades, e incluso de cierta desconfianza. Raúl Castro se debe a sus militantes, por lo que lleva a cabo un doble juego, pues en sus alocuciones reitera sus ideas antiimperialistas mientras le tiende la mano al Presidente Obama. Este, pese a que ha tratado de disociarse abiertamente de su antecesor, se encuentra en la etapa final de su mandato con un Congreso de mayoría republicana que no atenderá a su iniciativa de levantar el embargo. Las presidenciales del próximo mes de noviembre se presentan trascendentales, no solamente para La Habana con un posible giro al pasado, sino también para el panorama global. De manera que no se puede afirmar que estos nuevos aires se transformen en una ansiada normalización de las relaciones. De hecho, al margen del poderoso lobby republicano de los norteamericanos-cubanos de Florida, las nuevas generaciones y los integrantes de las últimas olas de migración, según un estudio de la Florida International University ${ }^{134}$, comienzan a demandar la terminación del embargo por un amplio margen de opinión del 72 por 100 y 79 por 100 respectivamente.

Por otra parte, procede subrayar que oportunidades que han comenzado a evidenciarse han avivado una conciencia aperturista en la que se busca in-

\footnotetext{
${ }^{134}$ Florida International University: 2016 FIU Cuba Poll: How Cuban Americans in Miami View U.S. policies towards Cuba. <https://cri.fiu.edu/research/cuba-poll/>.
} 
crementar el contacto entre ambos pueblos, bloqueados durante tantos años, al mismo tiempo que empiezan a vislumbrarse oportunidades en el ámbito económico y comercial, entre otros. Además, ha quedado patente que los más de cincuenta años de divergencias no han conseguido su objetivo sino simplemente empobrecer a la población isleña y proporcionar argumentos sólidos, aunque igualmente criticables, a los hermanos Castro para aferrarse a sus principios revolucionarios.

En lo concerniente a la UE, Federica Mogherini, no ha cejado en su empeño de «estar presente» en todo momento, ya fuese con la negociación del Acuerdo de Diálogo Político y Cooperación, en comparecencias conjuntas con su homólogo cubano ${ }^{135}$, o antes del viaje histórico de Obama a La Habana. No obstante, conviene poner de manifiesto que la Posición Común, continúa por el momento en vigor, debido a que todavía ha de ser estudiada la propuesta de revocación que Federica Mogherini anticipó a finales de septiembre de 2016. A su vez, el Parlamento Europeo, que siempre ha sido muy crítico con la situación de los derechos humanos y el tratamiento dispensado a la oposición al régimen cubano, tendrá que estudiar detenidamente el contenido del futuro instrumento político.

La falta de transparencia en las negociaciones ha generado, asimismo, malestar, porque no se ha alentado un debate abierto en lo referente al contenido o matices de lo rubricado a principios de año, como ha puesto de manifiesto el lanzamiento de una campaña, promovida por la organización sueca Civil Rights Defenders ${ }^{136}$ a favor de hacer público el todavía «proyecto». El Gobierno argumentó que se trataba de un asunto confidencial alegando que existía una línea muy desdibujada entre los dos ámbitos: lo público y lo confidencial. De manera que la petición se trasladó al Servicio Europeo de Acción Exterior, que a su vez alegó que dicha petición de transparencia podría socavar el proceso. Tal como se ha recogido en este trabajo en el apartado sobre el «activismo» del Parlamento Europeo, se apeló al Ombudsman Europeo, quien inició una investigación tras determinar que no se había actuado correctamen-

135 European Union External Action: HRVP Mogherini meets with Foreign Minister of Cuba, Bruno Rodriguez, 160922_11, New York, 22.09.2016. <http://eeas.europa.eu/headquarters/headquarters-homepage/10288/hrvp-mogherini-meets-with-foreign-minister-of-cuba-bruno-rodriguez-_en>.

${ }^{136}$ Civil Rights Defenders: EU and Sweden Strangling Transparency in Negotiations with Cuba, 29.08.2016, <www.civilrightsdefenders.org/news/svenska-eu-och-sverige-bryter-mot-offentlighetsprincipen-for-att-inte-riskera-relationen-till-kuba/>. 
te. Ese oscurantismo, que intenta presentarse como legitimado, despierta, sin embargo, ciertos recelos en diferentes sectores debido principalmente a que no se ha arrojado claridad acerca del elemento esencial relativo a los derechos humanos, a la implicación de la oposición en el exilio o a los medios para urgir una regeneración del sistema político cubano.

Ahora bien, conviene subrayar que el objetivo de la UE es claro: no perder su posición de primer socio comercial en el caso de que se levante el embargo, a pesar de que el comercio entre los dos vecinos -Cuba y EE.UU.- será más ágil y menos costoso que entre Bruselas y La Habana. En efecto, una vez más la UE defiende sus intereses reafirmando sus propios valores, pero aún queda por concretar cómo se conjugarán ambos en el futuro. Los próximos meses serán decisivos en la reintegración de Cuba a la escena mundial, pues se irá progresando en la culminación del Acuerdo tal como ha se han propuesto las partes, mientras que los norteamericanos elegirán una nueva Administración, y Venezuela, valedor del régimen cubano, quizás se encamine hacia una crisis todavía más profunda. 
